\title{
HISTORIA DE TRES CIUDADES. TIEMPOS DE OCUPACIÓN EN MADRID, ÁMSTERDAM Y PARÍS (1936-1945)
}

\author{
A history of three cities. Times of occupation in Madrid, Amsterdam, and Paris
}

(1936-1945).

\author{
Alejandro Pérez-Olivares. \\ Sciences Po Lyon. \\ alejandro.perezolivares@sciencespo-lyon.fr \\ Orcid: 0000-0001-7991-1437.
}

Cómo citar este artículo/Citation:

Alejandro Pérez-Olivares, "Historia de tres ciudades. Tiempos de ocupación en Madrid, Ámsterdam y París", Hispania Nova, 19 (2021): 792 a 836.

DOI: https://doi.org/10.20318/hn.2021.5898
Copyright: (C) HISPANIA NOVA es una revista debidamente registrada, con ISSN 1138-7319 y Depósito Legal M 9472-1998. Los textos publicados están -si no se indica lo contrario- bajo una licencia Reconocimiento-Sin obras derivadas 3.0 España de Creative Commons. Puede copiarlos, distribuirlos y comunicarlos públicamente siempre que cite su autor y la revista y la institución que los publica y no haga con ellos obras derivadas. La licencia completa se puede consultar en: http://creativecommons.org/licenses/by-nd/3.0/es/deed.es
Resumen: Este artículo reinterpreta las ocupaciones que definieron el marco de la "guerra total" desde la historia urbana y a partir de la comparación de tres ciudades: Madrid, Ámsterdam y París. Para ello, considera la influencia de fenómenos típicamente asociados al mundo urbano como el anonimato, la movilidad, la delicada distribución de recursos o la propia escala de las ciudades en el mantenimiento del orden de los regímenes de ocupación iniciados en 1939, 1940, 1944 y 1945. El texto se estructura a partir de tres estudios de caso: el tipo de administración durante la ocupación, civil o militar; la colaboración de la población con las autoridades y la construcción del orden posconflicto a partir de las rupturas $y$ continuidades que definieron las ciudades ocupadas.
Palabras clave: Ocupaciones - Historia urbana Guerra total - Orden público - Giro espacial.

Abstract: This article offers a reinterpretation of the occupations that defined the "total war" historical context from the perspective of urban history and by putting into comparison three different cities: Madrid, Amsterdam, and Paris. In order to do this, it considers the influence of several realities typically associated to the urban world such as anonymity, mobility, the delicate distribution of resources or the cities scale itself in the maintenance of the order initiated by occupation regimes in 1939, 1940, 1944, and 1945. The text is organized around three case studies: the type of administration during the occupation, civil or military; the collaboration of the population with the authorities and the construction of post-conflict order based on the 
ruptures and continuities that defined the occupied cities.
Keywords: Occupations - Urban History - Total War - Public Order - Spatial Turn.

"Do you remember the good old days before the ghost town? We danced and sang, and the music played in a de boomtown..."

(The Specials: Ghost Town).

\section{INTRODUCCIÓN*}

En mayo de 1940, Sally De Jong tenía veintiséis años. Criado en una familia judía pobre de Ámsterdam, logró licenciarse en medicina poco antes de que empezara la II Guerra Mundial, cuando las tinieblas empezaban a oscurecer el horizonte de su vida. Quizá pensara que, verdaderamente, era el peor de los tiempos. Los Países Bajos fueron ocupados por la Wehrmacht, Sally se separó de su familia y el contacto entre ellos se hizo cada vez más complicado. Su hermano gemelo logró escapar a Londres, desde donde participaba en el programa Radio Oranje, la voz de los holandeses en el exilio. En algunas ocasiones lograban pasar una carta a través de Portugal, en otras sólo era posible mediante el concurso de la Cruz Roja Internacional. A principios de 1943, Sally y su mujer pudieron esconder a sus hijos en un lugar seguro e intentaron escapar a Suiza, pero en la frontera los guardias les obligaron a pasar a Francia. Cruzaron el país y de nuevo en otra frontera, esta vez en la española, fueron detenidos como tantas otras personas aquellos años. Su rastro, a partir de entonces, se hizo casi invisible: su mujer murió en Auschwitz, él fue evacuado del campo en enero de 1945 hacia otro más pequeño, situado en Alemania central. No se sabe dónde, cuándo ni cómo murió. 43 años más tarde, su hermano gemelo, el famoso historiador holandés Louis De Jong,

\footnotetext{
* Este texto forma parte de las actividades del proyecto de investigación "La sociedad urbana en España, 1860-1983. De los ensanches a las áreas metropolitanas, cambio social y modernización" (PGC2018096461-B-C41). Está en deuda, asimismo, con el personal de la biblioteca del NIOD Institute for War, Holocaust and Genocide Studies (Ámsterdam) y del Centre d'Histoire de la Résistance et la Déportation (Lyon). Mi agradecimiento también se dirige a Rubén Muñoz Farrona, Santiago Gorostiza y Chema Sánchez Laforet, que revisaron el manuscrito original y compartieron sus útiles comentarios y precisiones.
} 
terminaba una conferencia en Harvard apelando a la imaginación, "esa facultad humana esencial para cualquier historiador", para recrear el pasado desde nuevos interrogantes ${ }^{1}$.

La historia que enmarcó la vida y la muerte de los hermanos De Jong fue producto de un contexto transnacional muy específico, el de la Europa ocupada durante el despliegue de la "guerra total". Un fenómeno complejo y polifacético, que conviene definir en plural, y que se ha convertido en uno de los temas más recurrentes en la agenda historiográfica europea y también más renovadores en cuanto a enfoques, fuentes y estudios de caso diferentes. Desde los frentes de batalla a las políticas de vigilancia y control, pasando por la dominación económica o consecuencias como el hambre y la escasez, el estudio de la II Guerra Mundial es cada vez más inseparable de las ocupaciones de territorios que conllevó, un enfoque transversal que pone en contacto experiencias, territorios y sujetos muy diferentes entre sí $^{2}$. Como recuerda Sophie De Schaepdrijver, en todos los casos los diversos regímenes de ocupación, que pueden definirse como el conjunto de instituciones, normas y propósitos implicados en la gestión de un espacio "nuevo", "ajeno" o "enemigo", se encontraron con poblaciones que estuvieron muy lejos de ser meros sujetos pasivos, espectadores de la violencia, la dominación y la explotación. A través de una guerra declarada o después de una anexión "pacífica", cualquier régimen de ocupación debe comprenderse más allá de sus disposiciones normativas ${ }^{3}$.

Es importante, así, comprender las ocupaciones de manera amplia, como contextos que desbordan la tradicional imagen asociada a tomar el control de un espacio o gestionar un territorio. Odile Debrash ya demandó esta amplitud de miras en la década

\footnotetext{
${ }^{1}$ Louis De Jong, The Netherlands and Nazi Germany (Cambridge : London, Harvard University Press, 1990), 3-5 y 24. Sobre los hermanos existe un documental, The Silent Historian (2011), realizado por Simonka De Jong, nieta del historiador.

${ }^{2}$ Adrian E. Wettstein, "Urban Warfare Doctrine on the Eastern Front", en Nazi Policy on the Eastern Front, 1941. Total War, Genocide and Radicalization, ed. Alex J. Kay; Jeff Rutherford y David Stahel (Rochester: University of Rochester Press, 2012), 45-72; Danielle Tartakowsky, "Les polices en pays occupés ou sous tutelle", en Pouvoirs et polices au XXe siècle, dir. Jean-Marc Berlière y Denis Peschanski (Bruxelles: Éditions Complexe, 1997), 127-135; Marcel Boldorf y Tetsuki Okazaki (eds.), Economies Under Occupation. The Hegemony of Nazi Germany and Imperial Japan in World War II (London: New York, Routledge, 2015); Tatjana Tönsmeyer; Peter Haslinger y Agnes Laba (Eds.), Coping with Hunger and Shortage under German Occupation in World War II, London, Palgrave Macmillan, 2018.

3 Sophie De Schaepdrijver, "Military occupations, 1914-1945", en The Cambridge History of War, Vol. IV. War and the Modern World, eds. Roger Chickering; Dennis Showalter y Hans Van De Ven (Cambridge, Cambridge University Press, 2012), 236-256; Cor Lammers, "Levels of Collaboration: A Comparative Study of German Occcupation Regimes during the Second World War", The Netherlands Journal of Social Sciences, 31 (1995), 3-31.
} 
de $\operatorname{los} 60$, cuando la ocupación empezó a transformarse en una "noción-encrucijada", originalmente fijada la mera actuación militar, para incorporar elementos del derecho o la ciencia política ${ }^{4}$. Esta amplitud ha sido recuperada, ya en nuestro presente, desde la tradición interdisciplinar de los estudios posconflicto para recordar que la edificación de cualquier régimen puede expresar tantas rupturas como continuidades con el contexto previo tras experimentar un proceso violento. La reconstrucción de los Estados, de los sistemas de gobierno (a escala nacional, pero también local), de la relación de la sociedad con las instituciones, las redes y espacios de sociabilidad o las normas que sostienen y explican el orden social está siempre mediada por la experiencia de un estado de excepción, la forma de gobierno basada en la supresión de la condición de ciudadanía ${ }^{5}$. En este sentido, cabe decir que las ocupaciones en la II Guerra Mundial descansaron sobre la base de la planificación y transformaron las esferas más importantes de la vida política y social en los territorios conquistados. En el contexto de la "guerra total", los gobiernos militares de transición establecieron acuerdos políticos y administrativos que determinaron las primeras etapas de la reconfiguración de las sociedades de posguerra, al tiempo que la práctica de salvaguardar el orden público en los territorios ocupados incluyó la creación de instrumentos para el control represivo, la persecución, la limpieza étnica y, en los casos más extremos, el genocidio ${ }^{6}$.

Este texto pretende aportar una reflexión novedosa a este vasto estado de la cuestión desde una perspectiva apenas tenida en cuenta hasta ahora: la historia urbana. Para ello, retomo una senda abierta por Jay Winter y Jean-Louis Robert hace algunas décadas y comparo el despliegue de diversos regímenes de ocupación a lo largo de tres ciudades, Madrid, Ámsterdam y París, entre 1936 y $1945^{7}$. A pesar de su relevancia en el devenir de los regímenes de ocupación que protagonizaron como capitales, el análisis desde la ciudad suele desaparecer de la historiografía tras los "momentos" en que fueron ocupadas, en favor de otros a escala nacional y desde enfoques como la historia política,

\footnotetext{
${ }^{4}$ Odile Debrash, L'occupation militaire (Paris, Librairie générale de droit et de jurisprudence, 1962).

${ }^{5}$ Christina Steenkamp, Violence and Postwar Reconstruction. Managing Insecurity in the Aftermath of Peace Accords (London : New York, Tauris, 2009); Giorgio Agamben, Estado de excepción. Homo sacer II, 1 (Madrid, Pre-Textos, 2010).

${ }^{6}$ Stephan-Ludwig Hoffmann et al., "Introduction. Seeking Peace in the Wake of War: Europe, 19431947”, en Seeking Peace in the Wake of War. Europe, 1943-1947, eds. Stephan-Ludwig Hoffmann et al. (Amsterdam, Amsterdam University Press, 2015), 9-27.

${ }^{7}$ Jay Winter y Jean-Louis Robert, Capital Cities at War. Paris, London, Berlin: 1914-1919 (Cambridge, Cambridge University Press, 1997).
} 
la vida cotidiana o las lógicas de exterminio. Los efectos de la ocupación holandesa se han interpretado tradicionalmente en términos de paradoja, mientras que sobre la francesa aún pesa el trauma de la colaboración con los ocupantes. ¿Por qué sólo el 25\% de los judíos holandeses sobrevivió a la guerra, frente al $40 \%$ en Bélgica o al $75 \%$ en Francia? ¿Qué importancia tuvo en ello la gestión del orden público en Ámsterdam? ¿Cómo superar la rígida dicotomía colaboración-resistencia, acuñada en los momentos posteriores a la "Liberación" de París, y ofrecer una explicación nítidamente urbana? ${ }^{8}$

Este artículo atiende a la dimensión urbana de un fenómeno transnacional, que puso en relación experiencias, planes y retos desiguales, diferentes miedos, protagonistas e instituciones. Madrid, Ámsterdam, París. Las tres fueron, de algún modo y en momentos distintos, ciudades-fantasma. Por las tres penetró el ejército ocupante aprovechando las grandes avenidas en su interior y su autoridad afectó a la libre disposición del espacio urbano, a la circulación e incluso al mero hecho de salir de casa en los instantes iniciales. Madrid y París fueron divididas en sectores, y en la primera esta decisión se prolongó en el tiempo para protagonizar la forma en que fue encauzada la represión. Ámsterdam y París se declararon "ciudad abierta", mientras que la ocupación de Madrid al final de la Guerra Civil se produjo tras 28 meses de asedio ${ }^{9}$. Pero, más allá de rastrear similitudes y diferencias, mi objetivo es analizar las expresiones singulares que caracterizaron estos contextos, una comparación lo suficientemente interesante y útil puesto que las tres ciudades experimentaron, en sí mismas, ocupaciones diversas: Madrid en 1939 (con una tentativa en 1936), Ámsterdam en 1940 y 1945 y París en 1940 y 1944.

En este sentido, entiendo la ocupación de estas tres ciudades como un fenómeno mucho más amplio que el simple dominio efectivo del espacio urbano, una realidad que trasciende un "momento" concreto, el de la entrada en la ciudad, y permite explicar la

\footnotetext{
${ }^{8}$ J. C. H. Blom, "The Persecution of the Jews in the Netherlands: A Comparative Western European Perspective", European History Quarterly, 19, 3 (1989), 333-351. El déficit urbano es particularmente patente en Anthony Beevor y Artemis Cooper, París. Después de la Liberación, 1944-1949 (Barcelona, Crítica, 2004).

${ }^{9}$ Para Madrid, Archivo General Militar de Ávila (AGMAV), Caja 4130, Carpetas 12, 13, 15, 16, 17 y 18 , y Alejandro Pérez-Olivares, Madrid cautivo. Ocupación y control de una ciudad (1936-1948), (Valencia, Publicacions de la Universitat de València, 2020), 27-58. Como se ha demostrado, cada distrito de la ciudad tenía al menos un tribunal militar asociado. Para París, David Drake, Paris at War. 1939-1944 (Cambridge, Harvard University Press, 2015), 38-69 y Jean-Paul Cointet, Paris 40-44 (Paris, Perrin, 2001), 26-31. Para Ámsterdam, Ad Windig, Amsterdam, from Occupation to Liberation (Eindhoven, Kempen, 1993).
} 
gestión del orden en ella. El siempre sugerente trabajo de Eric Carlton ya señalaba, hace tres décadas, que las ocupaciones son el contexto propicio para la imposición ideológica de los poderes ocupantes, para el ejercicio del poder en la orientación del orden social posterior y el desarrollo de múltiples formas de control, desde la asimilación y la aculturación a la coerción u otras formas más selectivas. Por su parte, Alice Hills insistió en la dificultad de explicar la reconstrucción del orden posconflicto sin tener en cuenta las ciudades, donde "orden" y "control” están estrechamente unidos. Ocupar una ciudad es hacerse cargo también de la gestión de sus recursos, sus miedos y expectativas, del simbolismo con el que está asociada y de un modo de vida marcada por el anonimato, la movilidad, la multiplicidad de espacios para el ocio, la sociabilidad y el encuentro con personas muy distintas o una expresión particular de las relaciones de género, clase o raza en el espacio público. Las diferentes formas de controlar una ciudad reproducen este orden propio, más que producir uno netamente nuevo ${ }^{10}$.

Las siguientes páginas están divididas en torno a tres imágenes del orden en la ciudad ocupada, que responden a diferentes contextos. ¿De qué manera estuvieron atravesados por realidades urbanas el tipo de administración de ocupación, civil o militar, las expresiones de la colaboración entre la población ocupada y los poderes ocupantes o la definición del orden posconflicto? Cada epígrafe muestra la relevancia de esta pregunta a partir de una realidad peculiar en una de las tres ciudades, lo que abre la puerta a la comparación. El primer estudio de caso se refiere a la huelga de febrero de 1941 en Ámsterdam e interpreta la crisis de la administración civil nazi en la Holanda ocupada a partir de un problema de orden público en la ciudad. El segundo recupera el fenómeno de los faux policiers en el París alemán, para reflexionar sobre los perfiles de la colaboración con las autoridades de ocupación. Por último, el tercer caso incide en la ocupación de Madrid por el Ejército franquista para reflexionar sobre el orden posconflicto a partir de la influencia de las rupturas y las continuidades en las lógicas de control urbano. Mi análisis pretende recuperar la complejidad de los regímenes de ocupación, y para ello ofrece una reinterpretación en clave urbana de trabajos ya publicados, pero también es empíricamente diverso. Así, trasciendo el mero estudio de las disposiciones oficiales para considerar también la importancia de las experiencias

\footnotetext{
${ }^{10}$ Eric Carlton, Occupation. The Policies and Practices of Military Conquerors (Savage, Barnes \& Noble Books, 1992); Alice Hills, Policing Post-Conflict Cities (London : New York, Zed Books, 2009).
} 
cotidianas de la población mediante la exploración de diversos tipos de egodocumentos (diarios, memorias) y fuentes judiciales (informes policiales, consejos de guerra). Asimismo, evaluaré el impacto de las ocupaciones en el espacio urbano, y las relaciones que éste permite, a partir de fotografias, y exploraré la producción de nuevas fuentes aprovechando las virtudes analíticas del llamado "giro espacial" para reconstruir las propias coordenadas de los regímenes de ocupación ${ }^{11}$.

\section{¿CÓMO ADMINISTRAR LA OCUPACIÓN?}

12 de marzo de 1941, Ámsterdam. Ópera Concertgebouw, al otro lado de la explanada del Museumplein: "Golpearemos a los judíos donde quiera que los encontremos, y todos aquellos que se relacionen con ellos deberán temer las consecuencias". Así resonaron las palabras centrales de la conferencia pública que el Reichskomissar Artur Seyss-Inquart, la máxima autoridad en el país ocupado, dirigió a los ciudadanos. Parecían lejanos los días en que, desde el exilio, la reina Guillermina y el gobierno habían ordenado a los funcionaros y representantes públicos mantenerse en sus puestos y no oponerse a la ocupación. A finales de mayo de 1940 y tras dos semanas de dominio militar, Seyss-Inquart, cuya hoja de servicios contaba con la experiencia del Anschluss en Austria y la ocupación de Polonia, confirmó la naturaleza civil de la administración y llamó al mutuo entendimiento, respeto y cooperación. Recomendado directamente por Himmler para el cargo, el gobierno de Holanda quedó repartido entre diferentes Comisariados Generales directamente subordinados a Seyss-Inquart y, a partir de éste, a Berlín, con el orden público y la justicia entre ellos. De este modo, la burocracia nombrada desde la capital del Reich supervisó a los cargos civiles holandeses “desde arriba" o los sustituyó ${ }^{12}$.

11 Ian N. Gregory y Alistair Geddes, "Conclusions: From Historical GIS to Spatial Humanities: Challenges and Opportunities", en Toward Spatial Humanities. Historical GIS \& Spatial History, Ed. Ian N. Gregory y Alistair Geddes (Bloomington: Indiana University Press, 2014), 172-185; Richard Rodger y Susanne Rau, "Thinking spatially: new horizons for urban history", Urban History, 47, 3 (2020), 372383.

12 Peter Romijn, "Managing the integration of the occupied Dutch territories in Hitler's empire", en Entrepeneurship in schwrierigen Zeiten. Unternehmertuum, Karrieren und Umbrüche während der ersten Hälfte des 20. Jahrhunderts, Hg. Peter Eigner; Herbert Matis y Andreas Resch (Wien, Liet Verlag, 2013), 309-330 y "The Experience of the Jews in the Netherlands during the German Occupation", en Dutch Jewry. Its History and Secular Culture (1500-2000), eds. Jonathan Israel y Reinier Salverd (Leiden, Brill, 2002), 253-271. La cita inicial en 261. 
Tanto los ocupantes como los ocupados comprendieron que las autoridades municipales eran esenciales para mantener el orden público y la vida cotidiana sin ápice de disturbios. Por parte de la Administración holandesa, estaban preparados para aceptar lo que ellos consideraban el "mal menor": trabajar bajo la supervisión del régimen de ocupación antes que abandonar a la sociedad (Imagen $\mathrm{n}^{\mathrm{o}} 1$ ). Un sentimiento que se vio alimentado cuando en el primer verano de la ocupación las milicias del NSB, el partido nazi holandés, tomaron las calles para intimidar a sus propios vecinos y enseñarles quienes eran los nuevos amos. Por otro lado, desde una perspectiva más amplia y cultural, las principales figuras dentro del Reichskommissariat estaban preparadas para importar la revolución nazi a un país "germánico y hermanado"13.

\section{Imagen no 1. Régimen “civil” de ocupación en los Países Bajos.}

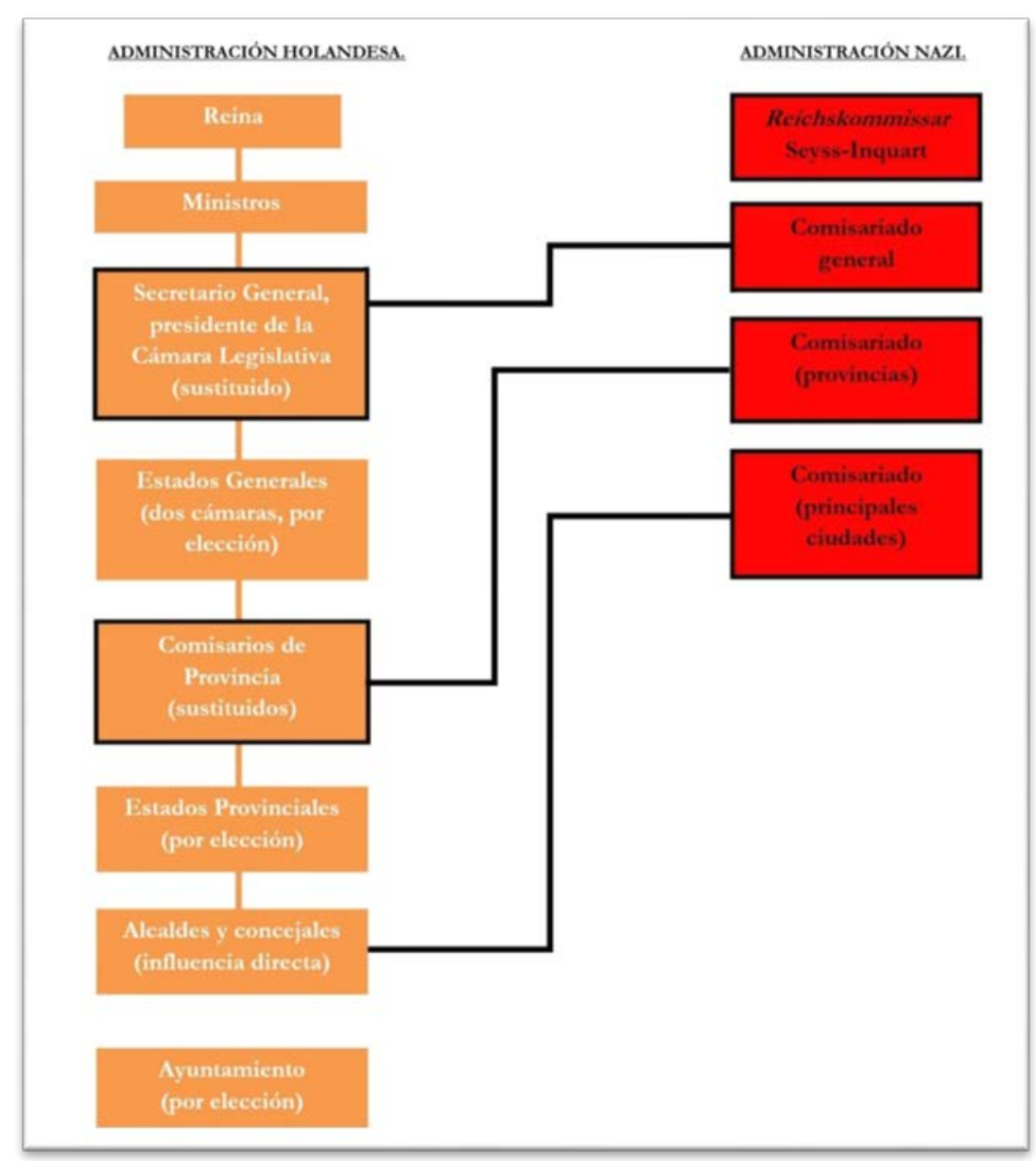

Fuente: Peter Romijn, "Ambitions and Dilemmas of Local Authorities in the German-

\footnotetext{
${ }^{13}$ Peter Romijn, “«The Lesser Evil». The case of the Dutch local authorities and the Holocaust”, en The Persecution of the Jews in the Netherlands, 1940-1945, Peter Romijn et al. (Ámsterdam, NIOD : Vossiuspers UvA, 2012), 13-26.
} 
Occupied Netherlands, 1940-1945", en Local Government in Occupied Europe (19391945), eds. Bruno De Wever; Herman Van Goethem y Nico Wouters (Gent, Academia Press, 2006), 33-66. Elaboración propia.

Tras la ocupación de Holanda la guerra continuó hacia el oeste, y pronto llegó a París. Después del armisticio en junio de 1940, Hitler situó un comandante militar para el gobierno del país, puesto que sólo el Ejército tenía el personal y los recursos para supervisar simultáneamente la ocupación y las fronteras del Hexágono mientras Alemania se preparaba para la invasión de Gran Bretaña. Los equilibrios entre la Wehrmacht, las SS, la Oficina para Asuntos Exteriores y las diversas ramas del partido nazi no siempre fueron estables ${ }^{14}$. Al mismo tiempo, el país había quedado dividido en tres demarcaciones: el régimen satélite de Vichy, la zona bajo ocupación directa y otra más al Norte, "prohibida" al tránsito, como frontera militar. En París se estableció el comandante militar, Alfred Streccius, reemplazado en octubre por Otto von Stülpnagel ${ }^{15}$.

Ésta fue la primera diferencia respecto a la ocupación de Holanda, pero no la única. El régimen de ocupación no sólo estuvo sostenido por las tropas alemanas, ya fuera aquellas destinadas a garantizar el orden público o las propiamente de combate. Antes de la ocupación, la administración cotidiana de una ciudad de 5 millones de habitantes descansaba en dos pilares: los prefectos de la Policía y del Sena y el Consejo Municipal. La ciudad fue gobernada desde criterios de orden público, lo que significó la práctica desaparición del Consejo en favor de los dos prefectos, cuyos poderes y autoridades se vieron reforzados ${ }^{16}$. La confianza en las instituciones civiles demostraba que bajo la ocupación subyacía un criterio de "proximidad", aunque con una estructura mixta. A pesar de que la máxima autoridad en la ciudad era militar, el gobernador del "Gran París", las instituciones municipales tuvieron un destacado papel en la colaboración con los alemanes. Tal y como sugirió Eric Carlton, la incorporación de

\footnotetext{
14 Thomas J. Laub, After the Fall. German Policy in Occupied France (1940-1944), (New York, Oxford University Press, 2010), 9-20.

${ }^{15}$ Richard Vinen, The Unfree French. Life Under Occupation (London, Penguin, 2007), 102-112; Cointet, Paris 40-44... 43-44 y Cécile Desprairies, Paris dans la collaboration (Paris, Seuil, 2009), 540, $183,237$.

${ }^{16}$ Peter Lieb y Robert Paxton, «Maintenir l'ordre en France occupée. Combien de divisions?», Vingtième Siècle. Revue d'histoire, 4, 112 (2012), 115-126 y Cointet, Paris 40-44... 51-54.
} 
Europa occidental a lo que se configuraba ya como un imperio formaba parte de una estrategia de "control selectivo" 17 .

Tan sólo un año antes, la ocupación de Madrid al final de la Guerra Civil española planteó un escenario diferente. Es indudable que, una vez acabados los enfrentamientos con el Ejército alemán, París y Ámsterdam fueron incorporadas a la amplia retaguardia de una guerra no terminada. En el caso de la capital de España, la ocupación significó la proclamación del estado de guerra, una realidad que implicaba la consideración del Ejército como la máxima autoridad en la ciudad, también a la hora de definir las conductas delictivas y los consiguientes castigos. A las consideraciones básicas para mantener el orden en la ciudad, como la protección del abastecimiento, las comunicaciones o la propiedad, pronto se unió la proyección del bando de guerra hacia atrás, hacia las actitudes sostenidas durante la guerra y más allá ${ }^{18}$.

Por eso los soldados que integraban la Columna de Orden y Policía de Ocupación también protagonizaron el registro de sedes de partidos y sindicatos, centros militares, lugares de la Administración, domicilios particulares e incluso hospitales, en busca de cualquier información que significara una mínima oposición a la sublevación de 1936. El profundo carácter político de la guerra, la voluntad del nuevo Estado franquista por orientar el orden social de posguerra, explica la labor de estos "Servicios Especiales", como se denominaban. La clasificación a efectos punitivos de la información que pudieron recoger fue una parte intrínseca de la intención de quebrar el anonimato urbano, donde se diluían las responsabilidades individuales ${ }^{19}$. Dentro de ese esquema, las autoridades civiles se situaron en un claro segundo plano en la gestión de la ciudad, tanto que incluso el Ayuntamiento y la Diputación Provincial integraban los servicios de la Columna con la labor de "servicios urbanos, bancarios y de índole varia" $^{20}$.

\footnotetext{
${ }^{17}$ Carlton, Occupation... 134-145.

${ }^{18}$ Bando de guerra de 29/III/1939, en $A B C, 30 / \mathrm{III} / 1939$. El debate sobre quien debía gestionar el orden público, los gobernadores civiles o militares, quedó resuelto en diciembre de 1937 en favor de los segundos. AGMAV, Caja 2551, Carpeta 19.

${ }^{19}$ Pérez-Olivares, Madrid cautivo... 70-75 y Jesús Espinosa Romero, "La Delegación del Estado para la Recuperación de Documentos en Madrid", en Madrid, una ciudad en guerra (1936-1948), eds. Daniel Oviedo Silva y Alejandro Pérez-Olivares García (Madrid, Los Libros de la Catarata, 2016), 133-158.

${ }^{20}$ AGMAV, Caja 2552, Carpeta 44.
} 
La condición de capitalidad también proyectó un fuerte simbolismo sobre estas ciudades, con diferentes resultados sobre la autoridad principal. Lo hizo, desde luego, sobre Madrid, aunque la ascendencia castrense estaba fuera de toda duda. A finales de marzo de 1939, después de 28 meses de asedio, ya se había diluido el mito de la ciudad resistente, emblema del “¡No Pasarán!” con el que se certificó el fracaso del asalto directo del ejército franquista en la ciudad en noviembre de 1936. Un fracaso que conllevó toda una reflexión sobre la ciudad desde los presupuestos del orden público y que explica en buena medida cómo se ocupó la ciudad finalmente. A medida que eso ocurría surgió otro mito, el de un "Madrid cautivo" que debía ser liberado por el ejército, con la misión de incorporarlo al "nuevo Estado" y recuperar el orden en su capital $^{21}$. Nación y urbe también parecían encarnarse en París durante el verano de 1944, lo que explica en buena medida el conflicto en torno a la gestión militarizada tras la "liberación" de la ciudad, "corazón del país cautivo" para el general De Gaulle. Lejos de los planes del Alto Mando aliado, que consideraba que la ciudad no era un objetivo prioritario y suponía, de hecho, un problema logístico, ésta fue la principal reclamación del jefe de la Francia Libre desde el desembarco de Normandía, y también la principal expresión del conflicto de poder desatado entre el Gobierno provisional de la República francesa (creado el 3 de junio) y el mando militar aliado. De hecho, una de las hipótesis que De Gaulle quería alejar de la realidad era el del "gobierno militar aliado de los territorios ocupados". Para ello, era fundamental promover una insurrección en la ciudad que mantuviera la unidad política de la Resistencia, ocupar la ciudad cuanto antes en auxilio de esa sublevación y que tanto la entrada en la ciudad como la gestión del orden fuera una maniobra exclusivamente "francesa" 22 .

El contexto de Ámsterdam al final de la II Guerra Mundial supone un buen contrapunto a las dos experiencias previas, aunque en todas confluya la declaración del estado de guerra. En Holanda, eso convirtió al general Eisenhower en la máxima autoridad, en un contexto donde el gobierno en el exilio se encontraba en una situación de debilidad institucional. La ciudad ya vivía bajo la ley marcial, declarada por Seyss-

\footnotetext{
${ }^{21}$ Zira Box, España, año cero. La construcción simbólica del franquismo (Madrid, Alianza Editorial, 2010), 47-69. La reorientación del orden público a partir de noviembre de 1936 en Alejandro PérezOlivares, "Objetivo Madrid: planes de ocupación y concepción del orden público durante la Guerra Civil española", Culture \& History Digital Journal 4, 2 (2015), doi: http://dx.doi.org/10.3989/chdj.2015.019.

${ }^{22}$ Martin Blumenson, "Politics and the Military in the Liberation of Paris", Parameters, 28,2 (1998), 414.
} 
Inquart en septiembre de 1944, y en los ocho meses que mediaron entre esa decisión y la ocupación aliada la gestión del orden público se hizo más inestable, aunque permaneció bajo gobierno alemán hasta el colapso del régimen de ocupación en mayo de 1945. Después de tomar el control de Ámsterdam, las tropas aliadas colaboraron con la administración y los restos de la sociedad civil (particularmente la Resistencia holandesa), de modo que el gobierno militar fue únicamente provisional y la gestión de la ciudad posconflicto recayó en las autoridades locales, de acuerdo a la Convención de La Haya de $1907^{23}$.

Todo lo contrario ocurrió cinco años antes, cuando la administración de Ámsterdam recayó en un régimen civil de ocupación que utilizó a las autoridades locales, tradicionalmente las más cercanas a las preocupaciones de los vecinos, como instrumentos del gobierno autoritario, de la vigilancia de la población y la persecución racial. A partir de mayo de 1940 Seyss-Inquart desarrolló desde Reichskommisariat un fuerte control, ya que en el complejo sistema administrativo holandés la responsabilidad de salvaguardar el orden público pertenecía a los alcaldes, bajo la supervisión del Ministro de Interior y del fiscal general, que actuaban como directores de Policía en las subdivisiones del Estado central. La administración civil también implicó la acumulación de cargos. El caso paradigmático fue el de Hanns Albin Rauter, que dirigió la Comisaría General de Seguridad Pública mientras representaba la mayor autoridad de las SS y era, simultáneamente, Jefe de Policía en la Holanda ocupada. En el momento de la ocupación nazi, Ámsterdam contaba con 2.400 agentes locales repartidos en siete comisarías y bastante enraizados en la comunidad debido a la escala de la ciudad (antes de la guerra reunía a unas 750.000 personas). Por todo ello, la orientación del orden público tenía como objetivo no dar argumentos para endurecer el régimen de ocupación $^{24}$.

\footnotetext{
${ }^{23}$ Peter Romijn, "Did Soldiers Become Governors? Liberators, Resistance and the Reconstruction of Local Government in the Liberated Netherlands, 1944-1945", en World War II in Europe: The Final Year, ed. Charles F. Brower (New York, St. Martin's Press, 1998), 265-288.

${ }^{24}$ Bob Moore, "Nazi Masters and Acomodating Dutch Bureaucrats: Working Towards the Führer", en Working Towards the Führer. Essays in Honour of Sir Ian Kershaw, Ed. Anthony McElligott y Tim Kirk (Manchester : New York, Manchester University Press, 2003), 186-204; Guus Meershoek, "The Amsterdam Police and the Persecution of the Jews", en The Holocaust and History. The Known, the Unknon, the Disputed and the Reexamined, Ed. Michael Berenbaum y Abraham Peck (Bloomington : Indianapolis, Indiana University Press, 1998), 284-300.
} 
Sin embargo, la "nazificación" de la Administración tuvo, en términos urbanos, una clara proyección hacia la alteración del orden, con enfrentamientos entre el Weerbaarheidsafdeling (WA), la rama paramilitar del partido nazi holandés, y la población. Sobre todo en el Este de la ciudad, donde se situaban los barrios con mayor densidad de vecinos judíos, y en espacios de ocio y sociabilidad como los bares, o medios de transporte como el tranvía, donde se colocaron carteles con la frase "Prohibido para judíos". La tensión creció a medida que a lo largo del otoño de 1940 se decretó la expulsión de los judíos de la función pública y el registro obligatorio de negocios e individuos, para lo cual las autoridades tuvieron que definir qué era ser judío. Una vez definidos los términos, los vecinos debían acudir al Ayuntamiento o cualquier oficina del censo y presentar allí un historial personal completo, un proceso que duró diez semanas. Con el cambio de año, las autoridades estuvieron en condiciones de introducir un sistema de identificación personal, que trataba de aliviar el anonimato propio del mundo urbano, pero la situación no hizo sino empeorar ${ }^{25}$.

A pesar de la influencia que recibían "desde arriba", los policías holandeses se limitaban a mantener el orden en la ciudad, lo que reforzó el sentimiento de aislamiento en una parte importante de la población. Al fin y al cabo, el 60\% de los judíos holandeses residían en Ámsterdam, representaban una décima parte de la población urbana $\mathrm{y}$, aunque atesoraban una larga tradición de integración, asimilación y secularización, no disponían de muchos contactos fuera de su comunidad. Las tensiones culminaron con una batalla urbana entre judíos y paramilitares del NSB, que entraron al Barrio Judío en la noche del 11 de febrero de 1941 y formaron marcialmente en la plaza Waterloo, donde el río Amstel empieza a abandonar el centro histórico de la ciudad y es encauzado a través de un gran canal. Uno de los participantes en los disturbios, Bennie Bluhm, recordaba aquella noche como "húmeda y neblinosa", y décadas después confesaba: "Dejamos que vinieran. Sabíamos que más allá, en las calles y callejones, al menos ochenta de nuestros hombres estaban esperando". Piet Wertheim también estaba allí, quizá era uno de los que esperaron a los escuadristas del WA: "Primero, él [un paramilitar de nombre Koot] discutió con alguien, le gritó que exterminaría a los judíos,

\footnotetext{
${ }^{25}$ Jacob Presser, Ashes in the Wind. The Destruction of the Dutch Jewry (Detroit, Wayne State University Press, 1988), 33-45; De Jong, The Netherlands... 6-8.
} 
a todos ellos. Le gritamos y le dijimos que viniera. Éramos un montón y estábamos preparados. Justo cuando uno de nosotros empezó el combate el resto nos unimos"26.

Los tumultos no cesaron ante las progresivas medidas de Seyss-Inquart, que empezaron a definir un severo régimen de ocupación, muy lejos del espejismo de mayo de 1940. Una prueba más de que estos contextos no son estáticos, y de que las expectativas de la población ocupada y sus actitudes hacia las autoridades ocupantes podían cambiar con el paso del tiempo, como ha demostrado Laurien Vastenhout ${ }^{27}$. Sin embargo, el primer desafío al orden impuesto ocurrió por sorpresa. El martes 25 de febrero de 1941 los trabajadores de Ámsterdam iniciaron una huelga en solidaridad con sus vecinos judíos y denunciar así las condiciones de persecución y aislamiento a las que estaban siendo sometidos. El detonante fue una serie de arrestos producidos al lado de la sinagoga en los días previos, sobre todo el 22 y el 23, filmados por el OversturmbannFührer Knolle, jefe de la Policía de Seguridad alemana en la ciudad, como muestra del esmero con el que los ocupantes se entregaban al control de la ciudad $^{28}$.

La primera protesta pública contra los nazis en la Europa ocupada ha sido tradicionalmente definida como una muestra de solidaridad de la población no judía, y sin embargo apenas se han resaltado sus componentes netamente urbanos. Programada como una concentración para repartir octavillas en Noordermarkt, una plaza junto al último de los canales concéntricos que rodean el centro histórico de Ámsterdam, en el barrio entonces obrero de Jordaan, la huelga supuso un profundo desafío al orden urbano, seguida en primer lugar por los tranviarios y las plantillas de recogida de basuras y obras públicas. Las protestas se extendieron por los numerosos muelles de la ciudad y el repertorio de acción incluyó el sabotaje de las líneas de tren y tranvía, junto

\footnotetext{
${ }^{26}$ Yehudi Lindeman y Hans De Vries, "«Therefore Be Courageous Too». Jewish Resistance and Rescue in the Netherlands", en Jewish Resistance Against the Nazis, ed. Patrick Henry (Washington DC, The Catholic University of American Press, 2014) 185-219. La cita en 195; Presser, Ashes in the Wind... 47. La proporción sobre el total de la población en Ronald W. Jansen, Anne Frank, Silent Witnesses. Reminders of a Jewish girl's life (Ámsterdam, RWJ, 2014), 55.

${ }^{27}$ Laurien Vastenhout, The Holocaust and the German Occupation of the Netherlands from the Perspective of Dutch Jewish Survivors (Tesis de Máster, Universiteit van Amsterdam, 2014).

${ }^{28}$ Presser, Ashes in the Wind... 51.
} 
con el bloqueo del acceso al centro de la ciudad, paralizada durante dos días ${ }^{29}$. Situar el conjunto de acciones que definieron la huelga sobre un plano permite comprender por qué las autoridades temieron perder el control de la ciudad, ya que una protesta contra las medidas anti-judías involucró al conjunto urbano. Destacan varios factores, más allá de los paros laborales en los puertos. En primer lugar, se bloquearon los accesos a la ciudad desde el Suroeste, con varios sabotajes en la estación Harleemmermeer, y desde el Noroeste, a lo largo del eje que comunicaba Ámsterdam con Sloterdijk. Por otro lado, el acceso al centro de la ciudad quedó obstruido en el entorno de la calle Vijzelstraat, una vía de comunicación fundamental a través del tranvía. El propio barrio del Jordaan fue aislado mediante diferentes acciones a lo largo de los puentes del Leidsegracht, un canal transversal a los tres principales que rodean la ciudad (Imagen $\mathrm{n}^{\mathrm{o}} 2$ ).

Entre los principales efectos de la "huelga de febrero" está la reconsideración del régimen de ocupación holandés. En primer lugar, se declaró el estado de emergencia y la agitación fue reprimida tanto por Hans Albin Rauter, máximo cargo de las SS, como por el Comandante en Jefe de las Fuerzas Armadas de los Países Bajos, el General del Aire Friedrich Christiansen. En segundo lugar, en términos de orden público, el desafío había sido mayúsculo, lo que condujo a la destitución del alcalde de Ámsterdam y la introducción del Führerprinzip, el "principio del caudillaje", en la conducción de la administración de ocupación. En tercer lugar, los diferentes servicios de policía holandesa (militar, provincial y del Estado) fueron disueltos y centralizados, en un largo proceso que duró hasta el año 1943. En ese contexto, sobre la gestión del orden en la ciudad y el futuro de la ocupación se empezó a proyectar el rumbo de la guerra. La salida a la crisis de febrero de 1941 incluyó otra serie de medidas contra los judíos: en otoño del mismo año su presencia fue prohibida en los mercados de la ciudad y los niños se vieron obligados a asistir a escuelas separadas ${ }^{30}$. Sin embargo, lo más importante fue el progresivo conocimiento que las autoridades adquirieron de ellos, algo patente en el Stippenkaart, el "plano de los puntos", donde la población judía aparece cuantificada y localizada por barrios. Finalizada en mayo de 1941, esta cartografía

\footnotetext{
29 Henk Van Der Molen, "Amsterdam offers resistance", Traces of War, 9 de octubre de 2016, https://www.tracesofwar.com/articles/2929/February-strike-February-25th-and-26th-1941.htm (última consulta, 23 de abril de 2020).

${ }^{30}$ Romijn: "Managing the integration... y "Ambitions and Dilemmas..., 228; Marnix Croes, "The Dutch Police Force and the Persecution of the Jews in the Netherlands", en Local Government... 67-81.
} 
representa con cada punto a diez judíos censados, y cada barrio tiene asociadas dos cifras: en rojo, la población judía; en azul, la no judía. Este plano, por tanto, puede considerarse como uno de los instrumentos más refinados del régimen de ocupación nazi en Ámsterdam.

Es necesario insistir en la influencia de la gestión urbana del régimen de ocupación para entender el exterminio sistemático de los judíos holandeses, que según algunos estudios llegó a corresponder con el $75 \%$ de la población de preguerra ${ }^{31}$. Gran parte de las decisiones que condujeron a lo que la historiografía ha denominado "la paradoja holandesa", es decir, el alto grado de víctimas mortales respecto a otros países, se explican desde esta quiebra del orden público urbano y la crisis de la administración civil. Entre ellas, destaca la labor del Consejo Judío, la expresión institucional de la colaboración de la comunidad judía de Ámsterdam con las autoridades de ocupación. Aunque su creación fuera anterior, existe un amplio consenso historiográfico para interpretar su despliegue operativo como una reacción a la huelga de febrero. Según Dan Michman, la fuerte posición de las SS y la Gestapo en Holanda se explica por el desarrollo de un régimen civil de ocupación, ya que tras la conquista del país no se creó un Departamento de Asuntos Judíos específico. El establecimiento del Consejo suponía el triunfo de las políticas de control de Albin Rauter y de arianización de Seyss-Inquart, y lo hacía además de un modo único en Europa occidental: con una clara subordinación a la autoridad de la policía alemana ${ }^{32}$.

\footnotetext{
${ }^{31}$ Lindeman y De Vries, “«Therefore Be Courageous... 185.

${ }^{32}$ Dan Michman, "The Uniqueness of the Joodse Raad in the Western European Context", en Dutch Jewish History, Vol. III, ed. Jozeph Michman (Jerusalem, 1993), 371-380. La paradoja en Ido De Haan, "Imperialism, Colonialism and Genocide. The Dutch Case for an International History of the Holocaust", BMGN - Low Countries Historical Review, 125, 2-3 (2010), 301-327.
} 
Imagen $n^{0}$ 2. La "huelga de febrero" y las consecuencias del régimen de ocupación de Ámsterdam.

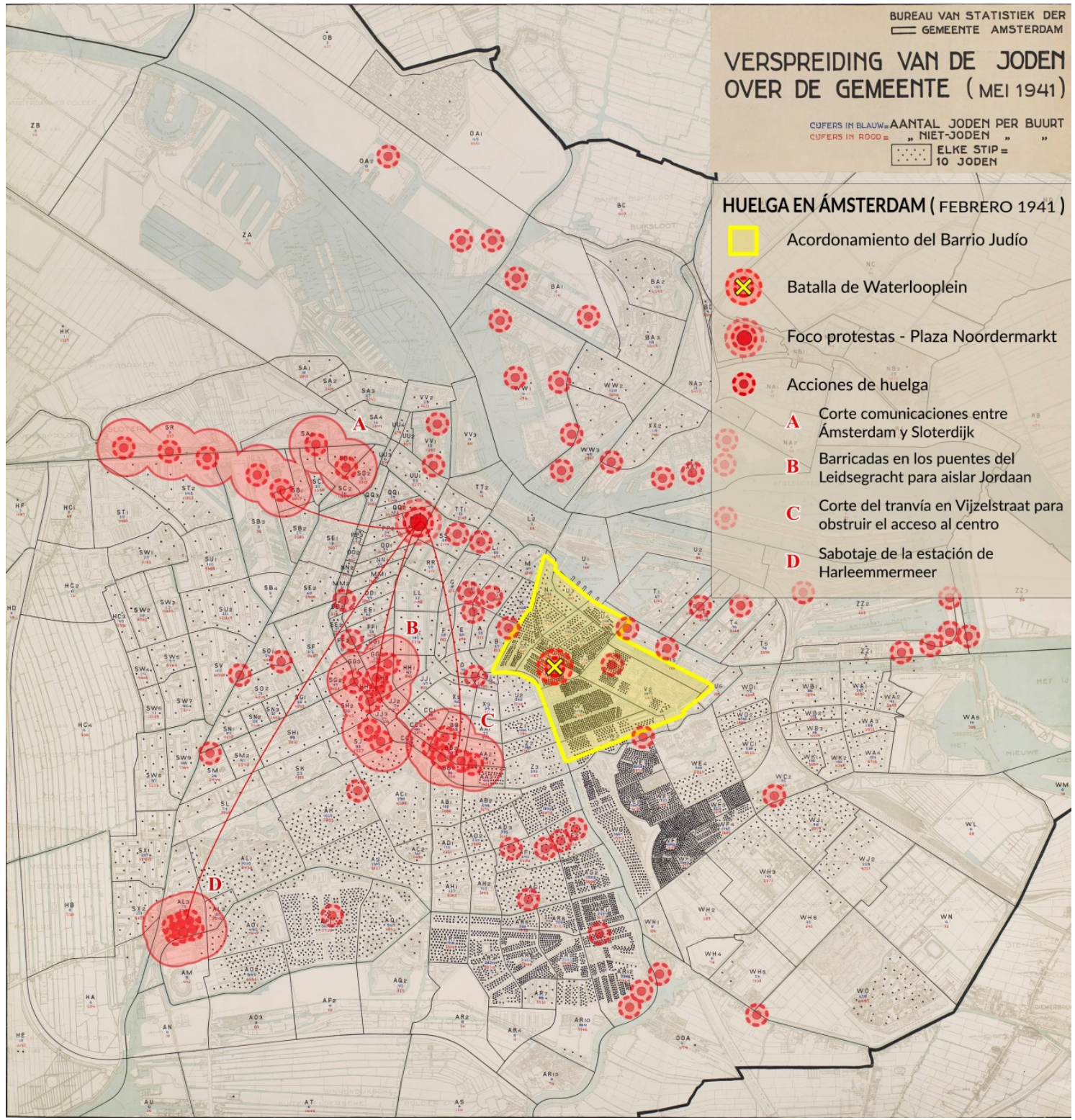

Fuente: NIOD Collection, Stippenkaart y Henk VAN DER MOLEN,

“Amsterdam offers”. Elaboración propia y de Chema Sánchez Laforet. 


\section{COLABORAR CON LOS OCUPANTES, GOBERNAR A LOS OCUPADOS.}

\section{"Pascal: - Quería informarte.}

Didier: - ¿De qué?

Pascal: De la agradable atmósfera de nuestra ciudad. ¡Qué vergüenza!

Didier: ¿Qué vergüenza es ésa?

Pascal: La policía. Es una vergüenza que la policía no haga nada y deje la ciudad en este estado..." "33.

Escrita durante la ocupación alemana de París, aunque iniciada antes de la guerra, La machine à écrire de Jean Cocteau explora los misterios que rigen la voluntad y las acciones de las personas cuando se remueven las normas que definen el orden social. Las conductas sometidas a una lógica ajena a la vida cotidiana, los efectos del anonimato en las relaciones sociales. El desorden de la "máquina de escribir", pseudónimo que en la obra envuelve toda una trama de crímenes, es el de las decisiones tomadas por individuos que no son sino intermediarios. Una muestra temprana del teatro del absurdo, producto de un contexto muy particular. No es difícil imaginar el París de Cocteau, ocupado por los nazis y por miles de máquinas de escribir manejadas por los agentes de policía. La misma policía que, según uno de los personajes de esa obra, no hacía nada. Puro teatro, puesto que la existencia de diferentes fuerzas policiales en la ciudad, respaldada de muchas formas por la autoridad alemana, fue una de las características de la ocupación. Además, la colaboración de ciudadanos anónimos con los nuevos administradores situó a la policía regular en una situación complicada, según Richard Vinen ${ }^{34}$.

Cooperar con las nuevas autoridades de ocupación a veces conllevaba la creación de ciertas instituciones que garantizaran el orden, como ocurrió en el caso del Consejo Judío de Ámsterdam. Y, nuevamente, las intenciones, las presiones "desde arriba" y la agencia "desde abajo", los contextos internos y externos, todo ello influyó

\footnotetext{
33 Jean Cocteau, La machine à écrire. Théâtre, Vol. II (Paris, Gallimard, 1983), 115.

${ }^{34}$ Vinen, The Unfree French... 128-130.
} 
en la conducción violenta de las ocupaciones. Junto al desempeño del Consejo fue importante la presencia de Sybren Tulp, antiguo militar destinado en las colonias y miembro del partido nazi local, el NSB, como nuevo jefe de Policía en la ciudad, cuyas acciones superaron las expectativas de sus superiores alemanes. A finales del verano de 1942, y a medida que las redadas contra los judíos se hacían cada vez más exigentes para los alemanes, Tulp ordenó a sus hombres emplearse durante cinco noches a la semana y concentrar a los presos en el Hollandsche Schouwburg, el "Teatro Holandés" ubicado en el barrio judío, o llevarles directamente a los andenes de la Estación Central $^{35}$. Willi Lages, jefe del Sipo-SD (policía política) en Ámsterdam, tenía claro la importancia de su labor:

"El principal apoyo de las fuerzas alemanas en labores de control y más allá fue la policía holandesa. Sin ella, no se habría cumplido el 10\% de las tareas de la ocupación alemana... También habría sido prácticamente imposible capturar ni siquiera al $10 \%$ de los judios holandeses sin ellos" ${ }^{, 36}$.

Según el historiador Louis De Jong, el miedo, la división y la decepción también fueron herramientas útiles para promover la cooperación durante la ocupación ${ }^{37}$. Es posible ir más allá, sin embargo, desde la historia urbana. Realidades constitutivas de la ciudad como la movilidad, el anonimato, la disociación de los lugares de trabajo y ocio o su propio tamaño explican la necesidad de la colaboración ciudadana, pero no explican por sí mismas su desarrollo efectivo. El ejemplo de Madrid en 1939 resulta ilustrativo. Una vez asegurado el control del espacio urbano a través del despliegue de las unidades militares y la proclamación del bando de guerra, la Auditoría de Guerra del Ejército de Ocupación publicó un edicto llamando a la cooperación de los vecinos, especialmente serenos, porteros e inquilinos ${ }^{38}$. Este texto puede ser interpretado a partir de muchos puntos de vista, pero, desde una perspectiva netamente urbana, quizá lo más interesante sea preguntarse por qué la máxima autoridad judicial en el Madrid ocupado

\footnotetext{
${ }^{35}$ Croes, “The Dutch Police Force... 79; Moore, "Nazi Masters... 191-193.

${ }^{36}$ NIOD Collection, I-998, O-3. Cita traducida al inglés en Moore, "Nazi Masters... 194.

${ }^{37}$ De Jong, The Netherlands... 9-17.

38 "Edicto de la Auditoría de Guerra del Ejército de Ocupación", 30/III/1939, en ABC, 1/IV/1939.
} 
reconocía su incapacidad para penetrar por sí misma en el haz de relaciones que conformaba su jurisdicción. La elección de figuras a medio camino entre el espacio público y el privado, como los serenos, y el interés por indagar en las relaciones vecinales apuntan a la voluntad de encontrar en la vida cotidiana las responsabilidades criminales según el bando de guerra. La amenaza de la ley marcial y la necesidad de información explican la coerción que protagonizó la posguerra madrileña, con el edicto como una de las principales cartas de presentación de la dimensión violenta del régimen franquista en la ciudad ${ }^{39}$.

A pesar del impacto de la ocupación en la población, cuestiones como las subjetividades o la agencia son centrales para ponderar la colaboración de la población con las autoridades, mediada tanto por la coerción como por la oportunidad de la restitución social o simbólica. Como ha resaltado Daniel Oviedo, la participación forzosa de los porteros fue tan sólo una entre las muchas formas que adoptaron las prácticas acusatorias en el Madrid de posguerra ${ }^{40}$. La gestión de la información fue una constante en los regímenes de ocupación, bien a efectos punitivos, bien para desarrollar lógicas de vigilancia. En París las autoridades alemanas también obligaron a todos los porteros a ayudar a la policía. Tenían que informar, por ejemplo, de los nuevos inquilinos a las 24 horas de su llegada o identificar visitantes que estuvieran más de una noche o dos, algo fundamental puesto que los archivos policiales habían sido evacuados junto el resto de la documentación oficial ${ }^{41}$. Entender este sutil equilibrio entre las necesidades de los ocupantes y el mantenimiento de una relación cotidiana pasa por comprender la realidad de "vivir con el enemigo" más allá de un esquema binario dominación-resistencia ${ }^{42}$.

En París, además, la situación mostraba grandes dosis de segregación en el espacio. Los ocupantes se instalaron principalmente en los distritos al Oeste de la

\footnotetext{
39 Daniel Oviedo Silva y Alejandro Pérez-Olivares, “¿Un tiempo de silencio? Porteros, inquilinos y fomento de la denuncia en el Madrid ocupado", Studia Historica. Historia Contemporánea, 34 (2016), 301-331.

40 Daniel Oviedo Silva, "«Juro por Dios y declaro por mi honor»: verdad, impostura y estrategias autoexculpatorias en las declaraciones de la posguerra madrileña", en Madrid, una ciudad..., 159-214.

${ }^{41}$ Donald Rosbottom, When Paris Went Dark. The City of Light Under German Occupation, 1940-44 (London, John Murray, 2014), 51, 113, 136 y 168-170.

${ }^{42}$ Sobre esta última cuestión ha insistido Robert Gildea, Marianne in Chains. Daily Life in the Heart of France During the German Ocupation (London, MacMilan, 2002), 65-68. Véase también Drake, Paris at War..., 61-87 o Laub, After the Fall..., 49-70, para una perspectiva desde el orden público.
} 
ciudad, y su presencia en la margen superior del Sena, en el Norte, el Este y los suburbios industriales que rodeaban la capital fue relativamente liviana. Si algún parisino quería pasar desapercibido, era más fácil hacerlo en las callejas de barrios como Belleville o Ménilmontant entre los distritos XIX y XX que en las grandes avenidas y los bulevares abiertos a lo largo de los distritos VIII y XVII, cerca de los edificios públicos requisados por los alemanes. Pero su presencia no era sólo una cuestión de espacio, también de tiempo. La posibilidad de toparse con ellos, y las consecuencias de ese encuentro, dependían también de la proximidad del toque de queda, que alteró el día a día de los habitantes de la ciudad. París estaba, de muchas formas distintas, a la "hora alemana”. Sólo los oficiales podían habitar libremente la noche, y por la mañana las calles les pertenecían a ellos también, junto con los policías franceses ${ }^{43}$.

La posibilidad del contacto con los alemanes no dependía únicamente del anonimato amparado por el tamaño de la ciudad o la clandestinidad sancionada por el horario. Tanto la ocupación concreta de la ciudad como la evolución de la guerra dibujaron una serie de lugares nuevos, cotidianos: los espacios del mercado negro, destinados al intercambio clandestino y con vocación de poner en contacto directo a los ocupantes con los ocupados. Al volver a la ciudad después del verano de 1940, el crítico de arte y periodista de extrema derecha Maurice Bardèche recordaba cómo "algunos espectáculos nuevos nos enseñaron rápidamente las realidades de la guerra”. Las filas del racionamiento delante de las tiendas ocupaban lugares familiares, como el mercado de la Rue Mouffetard al que solía ir, produciendo un efecto de extrañamiento en su percepción de la ciudad. Simpatizante de los ocupantes, sus recuerdos filtran los encuentros cotidianos con ellos en este tipo de espacios. "La presencia de los soldados alemanes no era la más pesada de todas. No los vimos mucho en la Rue Mouffetard. La insolencia de los primeros transportistas del mercado negro fue más difícil de soportar" $" 44$.

El testimonio de Bardèche es importante para evaluar una de las consecuencias más graves en la vida cotidiana de los parisinos, y es que en el mismo verano de 1940

\footnotetext{
43 Vinen, The Unfree French..., 130-132. La expresión entrecomillada se refiere al clásico libro de Philippe Burrin, La France à l'heure allemande, 1940-1944 (Paris, Seuil, 1995).

${ }^{44}$ Maurice Bardèche, Souvenirs (Paris, Buchet-Chastel, 1993), 101 y 111. La simpatía ideológica por los nazis no dejaba de señalar la participación, "oficial o extraoficial", de los alemanes en el mercado negro, como sentencia Rosbottom, When Paris..., 135.
} 
comenzaron los problemas de abastecimiento en la ciudad. En su diario no había espacio para reflexionar sobre los mercados como un lugar de expresión de la agencia femenina. Una realidad que, como sugirió Paula Schwartz, no se puede explicar si se reduce el comportamiento de los ocupados a esquemas binarios de colaboración-resistencia. Y es que, tanto para la policía parisina como para quien protestaba, la "lucha por el pan" fue una tarea plenamente feminizada ${ }^{45}$. A pesar de las gestiones de los prefectos del Sena y de la Policía, las autoridades administrativas, tanto en los barrios burgueses del Oeste como en los más populares las privaciones se agravaron con la vuelta de la población emigrada antes de la entrada alemana en la ciudad. En los mercados, los puestos de pescado y aves de corral permanecían todavía cerrados, uno de los síntomas más fiables en la ciudad de la alteración que supuso la ocupación, aunque todavía abundaban las verduras, las frutas y los productos lácteos. No tardó en cambiar esa situación: en los dos primeros años de ocupación, el consumo de leche descendió a la mitad, y el de carne, a menos de un tercio. Por mencionar dos bebidas sin las que no se entendía la sociabilidad, el café y el vino se volvieron más difíciles de encontrar. Pronto apareció un nuevo tipo de parisinos: los operadores del mercado negro, que rigieron la alimentación de los vecinos junto a los impuestos del ejército de ocupación. Como consecuencia, durante la presencia alemana en la ciudad el coste de la vida aumentó en un 166\%. Las primeras medidas tomadas incluían la limitación a tres platos de los menús en los restaurantes, así como fijar la ración de pan a 350 gramos por persona ${ }^{46}$.

El otoño trajo consigo el agravamiento de las condiciones de vida, desnudando de manera dramática la dependencia que la ciudad tenía del exterior. A pesar de la entrada en vigor de la cartilla de racionamiento en agosto era difícil conseguir alcanzar un mínimo calórico, sobre todo cuando la ciudad fue también ocupada por el invierno. La entrada del 8 de enero de 1941 en el diario del escritor Jean Guéhenno fue testigo de que la vida en París empezaba a ser difícil debido al desabastecimiento: "Tenemos los tickets, pero ya no permiten obtener nada. Las tiendas están vacías. Desde hace quince días, en casa hemos vivido sólo a base de los envíos de amigos y de los primos

\footnotetext{
${ }^{45}$ Paula Schwartz, "The politics of food and gender in occupied Paris", Modern \& Contemporary France, 7, 1 (1999), 35-45.

${ }^{46}$ Peter Davies, France and the Second World War. Occupation, collaboration and resistance (London : New York, 2001), 14-15; Cointet, Paris 40-44..., 33; Gildea, Marianne in Chains..., 79-86.
} 
bretones" ${ }^{47}$. Antes, la policía ya había alertado de las consecuencias para el orden público si la situación se prolongaba:

"Nuestra opinión es unánime: si esta situación continúa, el hambre y el frío nos llevarán a los movimientos callejeros. Su violencia y carácter son tanto más ciertos cuanto que la multitud está siendo deliberadamente acosada por la autoridad de ocupación, la cual, según ella, reduciría gradual pero continuamente el suministro de alimentos a París ${ }^{\text {,48. }}$.

París tenía frío y hambre, "París ya no come castañas en las calles". Tenía razón Paul Éluard en su poema Courage, escrito en 1943. Como contexto excepcional, la ocupación alteró la vida cotidiana de los vecinos de la ciudad, pero dibujó al mismo tiempo importantes continuidades. Los bares, que daban la bienvenida a nuevos rostros, códigos y acentos, siguieron siendo importantes lugares de sociabilidad. Según el diario de Jean Cocteau, el cabaret Le Boeuf era el bar más célebre de París, y allí se encontraban las diferentes costumbres francesas y alemanas, proyectadas también sobre la forma de bailar de ellos o los vestidos de ellas ${ }^{49}$. Los encuentros franco-alemanes podían adoptar muchas formas distintas, pero siempre eran más frecuentes en los lugares donde la ocupación se hacía más presente. Cerca de los Campos Elíseos, una veintena de bares conformaban el centro de las apuestas clandestinas ("les paris mutuels clandestins"), donde las carreras de caballos fueron sustituidas por grandes cantidades de carne o vino como objeto de puja, el primer paso para alimentar el mercado negro en la ciudad. En el mismo distrito, el restaurante Aux Deux Cocottes era uno de los lugares frecuentados por famosos traficantes quienes, en función de sus contactos con la administración de ocupación, se dejaban ver de manera más o menos abierta ${ }^{50}$. El antiguo miembro de Action Française Henry Charbonneau, procesado después de la guerra por colaboracionismo, reconoció abiertamente en sus memorias que había

\footnotetext{
${ }^{47}$ Cointet, Paris 40-44..., 122-129. La entrada de diario en 124.

48 Informe del 22/XII/1940 al Ministerio de Abastecimiento, creado por Vichy, citado en Paula Schwartz, "The politics of food..., 38 .

49 Jean Cocteau, Journal 1942-1945 (Paris, Gallimard, 1989), 40.

${ }^{50}$ Cécile Desprairies, Paris dans la Collaboration..., 250 y 594.
} 
restaurantes identificados de manera clara con el mercado negro, sobre todo en los barrios donde la presencia alemana era más densa ${ }^{51}$.

El fenómeno de los "restaurantes de mercado negro" se extendió a lo largo de la ciudad durante la ocupación. Como ha puesto de manifiesto Kenneth Mouré, adentrarse en estos espacios supone complejizar la colaboración en un contexto de desigual distribución de los alimentos, donde los propietarios de los restaurantes demostraron una gran creatividad para encontrar métodos alternativos de suministro ${ }^{52}$. Pero, desde una perspectiva urbana, el mercado negro habla de las múltiples posibilidades que la ciudad otorgaba en términos de movilidad, anonimato y diversificación de los contactos. Las tres realidades se combinaron con la penuria económica, el contexto bélico, la estructura policial de ocupación y la alteración del orden previo para proyectarse sobre los numerosos faux policiers que aparecieron en la ciudad. Según Richard Vinen, la Prefectura de Policía de París registró centenares de delitos atribuidos a falsos agentes de policía desde finales de 1941. Algunos trabajaban para los alemanes; otros eran desertores, cuando el rumbo de la guerra empezó volverse en contra de la Wehrmacht; el resto engrosaba las filas del ejército de reserva del mercado negro. Todos se buscaban la vida en una ciudad en guerra. Aprovechaban la oscuridad de la noche, tras el toque de queda, los salvoconductos especiales que les daban las autoridades e incluso algunos uniformes robados de los cuarteles a los que tenían acceso ${ }^{53}$.

Ser un faux policier era lo más parecido a tener una profesión real para los parisinos más pobres y marginados, acaso la única posibilidad de comer a lo largo del día, o la oportunidad de completar una maltrecha economía cotidiana al ser una parte integrante de las redes del mercado negro en la ciudad ${ }^{54}$. El fenómeno se extendió tan rápidamente que el Ministerio de Interior pidió explicaciones a la Prefectura en mayo de 1942, cuando en la prensa diaria las viñetas satíricas ya amplificaban su resonancia. Se

\footnotetext{
${ }^{51}$ Henry Charbonneau, Les Mémoires de Porthos, t. II (Paris, Desroches, 1969), 284.

${ }^{52}$ Kenneth Mouré, “La Capitale de la Faim: Black Market Restaurants in Paris, 1940-1944”, French Historical Studies, 38, 2 (2015), 311-341.

53 Richard Vinen, "False Policeman, Real Crooks, and Fictional Detectives in Paris during the Occupation”, Historically Speaking, 8, 3 (2007), 31-32.

${ }^{54}$ Una experiencia similar a la del protagonista de la película de Louis Malle, Lacombe Lucien (1974). El paralelismo con la realidad de Ámsterdam es la colaboración de Dries Riphagen con los servicios de inteligencia de las SS (el Sicherheitsdienst, SD) en el arresto de judíos. También se hizo una película: Riphagen (2016), dirigida por Pieter Kuijpers.
} 
configuraron incluso bandas organizadas, una de las más famosas fue la de Henry Chamberlain, alias Lafont, especializada en el tráfico de oro. Supuesto jefe de la "Gestapo francesa", situada en el número 93 de la Rue Lauriston (en el distrito VIII, junto a los edificios oficiales requisados por los ocupantes), Lafont actuaba con protección y salvoconducto alemanes, lo que muestra una vez más la importancia de la proximidad a la administración de ocupación y la segregación en el espacio que produjo ésta $^{55}$. El fenómeno ha sido interpretado mayoritariamente en términos económicos, alentado por una administración alemana capaz de distorsionar las propias normas de la ocupación para maximizar la explotación, según Grégory Auda. Si la policía tenía como tareas la vigilancia y la defensa de la propiedad, durante la ocupación fue utilizada para extraer recursos y derivarlos hacia la maquinaria de guerra alemana. Para Richard Vinen, el aumento de este tipo de casos fue un síntoma de la propia extensión de un mercado paralelo al oficial, que tuvo como consecuencia lo que define como "las posibilidades comerciales de la vigilancia policial" ${ }^{, 56}$.

Es posible llevar la interpretación a unos términos netamente urbanos. Por supuesto, los falsos policías del París ocupado demostraban que el orden público en la ciudad era una realidad dinámica, que debe ser comprendida más allá de las disposiciones oficiales y de las agencias de control como un conjunto de experiencias "a ras de suelo". Es más, puede decirse que ese mismo orden estaba en disputa: entre los policías que perseguían el mercado negro y quienes lo conformaban, entre la policía de Vichy y la Prefectura de París o entre las autoridades alemanas de ocupación y quienes se aprovechaban de sus medidas (el toque de queda, los salvoconductos o incluso la oscuridad como elemento de defensa pasiva), aunque cooperasen de manera continuada. Tanto el anonimato provisto por la escala de la ciudad, de tres millones de habitantes, como la movilidad articulada a través de los mismos medios de comunicación (más de un millón de parisinos utilizaban el metro en 1942) fueron profundos desafíos para las

\footnotetext{
${ }^{55}$ Kenneth Mouré, "The Faux Policier in the Occupied Paris", Journal of Contemporary History, 45, 1 (2010), 95-112; François Brioche, Dictionnaire de la Collaboration. Collaborations, compromissions, contradictions (Paris, Belin, 2014), 25, 53, 151, 156, 198, 219, 231, 239, 297, 331, 366, 399, 518, 532, 545-546, 574, 580, 592, 636, 658, 879. Sobre la banda "Bonny-Lafont" y sus conexiones con el mercado negro y los servicios de inteligencia nazis puede verse Fernando Castillo, Noche y niebla en el París ocupado: traficantes, espias y mercado negro (Madrid, Fórcola, 2012), 70-133.

56 Gregory Auda, Les Belles Années du 'milieu' 1940-1944. Le grand banditisme dans la machine répressive allemande en France (Paris, Michalon, 2013), 39-92; Vinen, The Unfree French..., 239-242. La cita entrecomillada en Vinen, "False Policeman...
} 
autoridades de ocupación. París no tenía rostro, como experimentaron con sorpresa los soldados que recorrían la ciudad en metro, o quizá sea más acertado decir que tenía demasiados. A finales de 1942, el Alto Mando Militar alemán fue sustituido por la Gestapo en las labores de vigilancia policial de la población ${ }^{57}$.

Esta decisión coincidió con el apogeo de un fenómeno que, en perspectiva, puede interpretarse como la subversión de uno de los pilares del régimen de ocupación nazi. En cooperación con las autoridades alemanas o actuando en beneficio propio, les faux policiers hacían un uso privativo de una de las características del mundo urbano, la movilidad, gracias a unos salvoconductos que sancionaban el privilegio de la libertad de movimientos en un contexto de amplias restricciones. Ya había ocurrido en Madrid, primero cuando las unidades militares introdujeron estos documentos y luego con la obligación de solicitar permiso al gobernador civil para cualquier desplazamiento fuera de la ciudad ${ }^{58}$. También en Ámsterdam, donde el espacio urbano se transformó a medida que las autoridades prohibían el tráfico (e incluso el acceso) a ciertos lugares de la ciudad, como la Estación Central, la plaza Dam o el propio Barrio Judío, que incorporaron barreras y alambres de espino a su mobiliario tradicional (Imágenes $\mathrm{n}^{\mathrm{o}} 3 \mathrm{y}$ $\left.n^{\circ} 4\right)$. En París, gran parte de los testimonios y recuerdos sobre la ocupación destacan que las vidas, simplemente, "se estrecharon" debido al control de los movimientos y la vigilancia de las $\operatorname{conductas}^{59}$. Entender la ocupación como un proceso también "urbanizador", la creación de espacios físicos y no físicos nuevos para gobernar la ciudad, así como la actuación sobre las propias experiencias o las percepciones urbanas, supone apuntar a la creación acelerada de nuevas alteridades en su interior. De este modo, la segregación y la fragmentación del espacio urbano también definieron los regímenes de ocupación ${ }^{60}$.

\footnotetext{
${ }^{57}$ Rosbottom, When Paris Went Dark..., 136 y 182-186.

${ }^{58}$ AGMAV, Caja 2584, Carpeta 4 y Archivo General de la Administración (AGA), Gobierno Civil de Madrid, solicitudes de salvoconductos. Cajas 45, 58, 59 y 67.

${ }^{59}$ Rosbottom, When Paris Went Dark..., 167.

${ }^{60}$ Un proceso similar pero sostenido en el "tiempo largo" en Hélène Noizet, "Spaces and spatialities in Paris between the ninth and nineteeth centuries: urban morphology generated by the management of otherness", Urban History, 47 (2020), 1-20. La teorización del "espacio producido" y la relevancia de las percepciones y vivencias en los clásicos Henri Lefebvre, La producción del espacio (Madrid, Capitán Swing, 2013 [1974]) y Edward Soja, Thirdspace. Journeys to Los Angeles and Other Real-and-Imagined Places (Malden, Blackwell, 1996).
} 
Imagen $n^{\circ}$ 3. Acceso clausurado al Barrio Judío, Ámsterdam (ca. 1942).

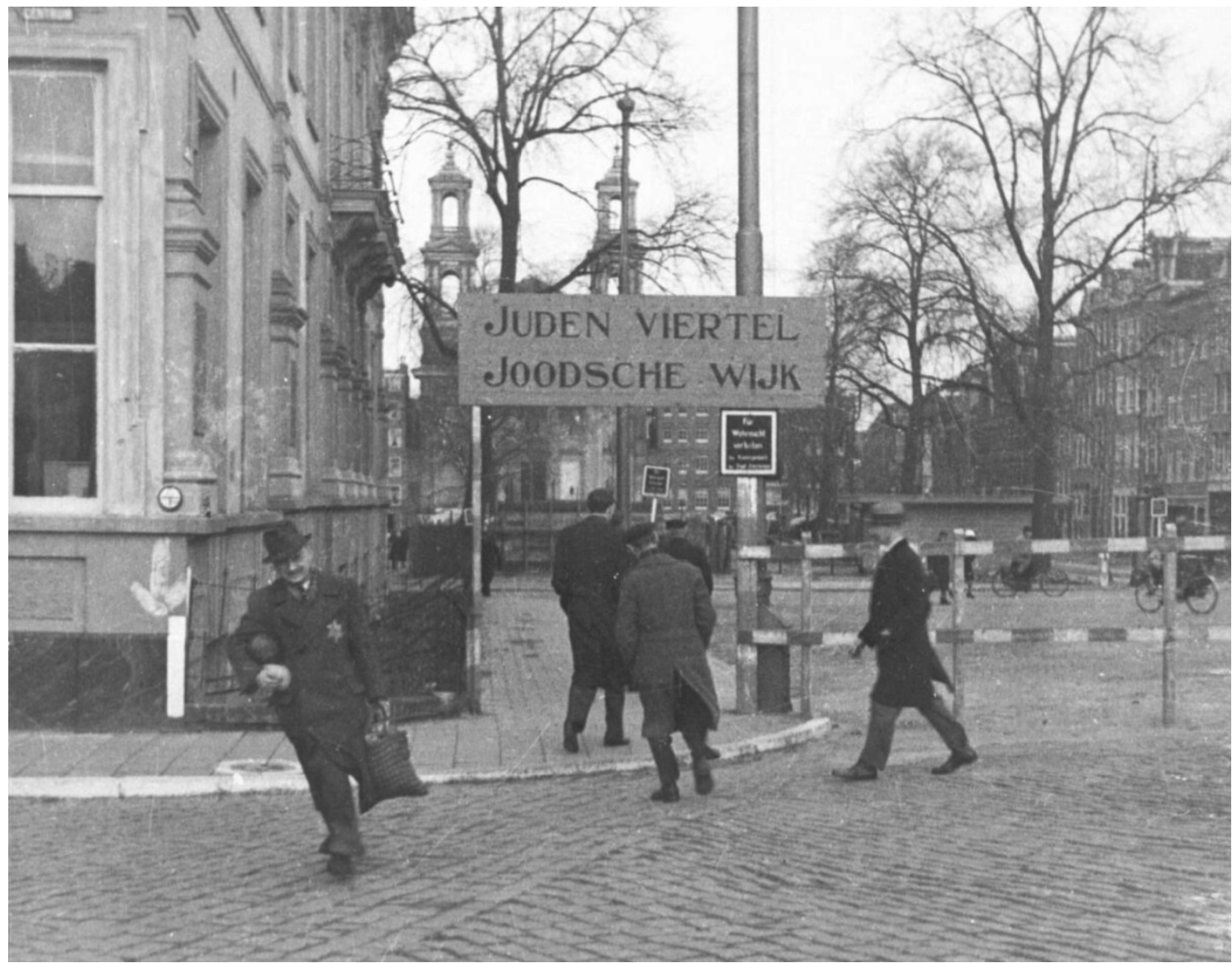

Fuente: NIOD Collection, 97016. 
Imagen $n^{0}$ 4. Limitación del tráfico en torno a la Centraal Station, Ámsterdam (1944-1945).

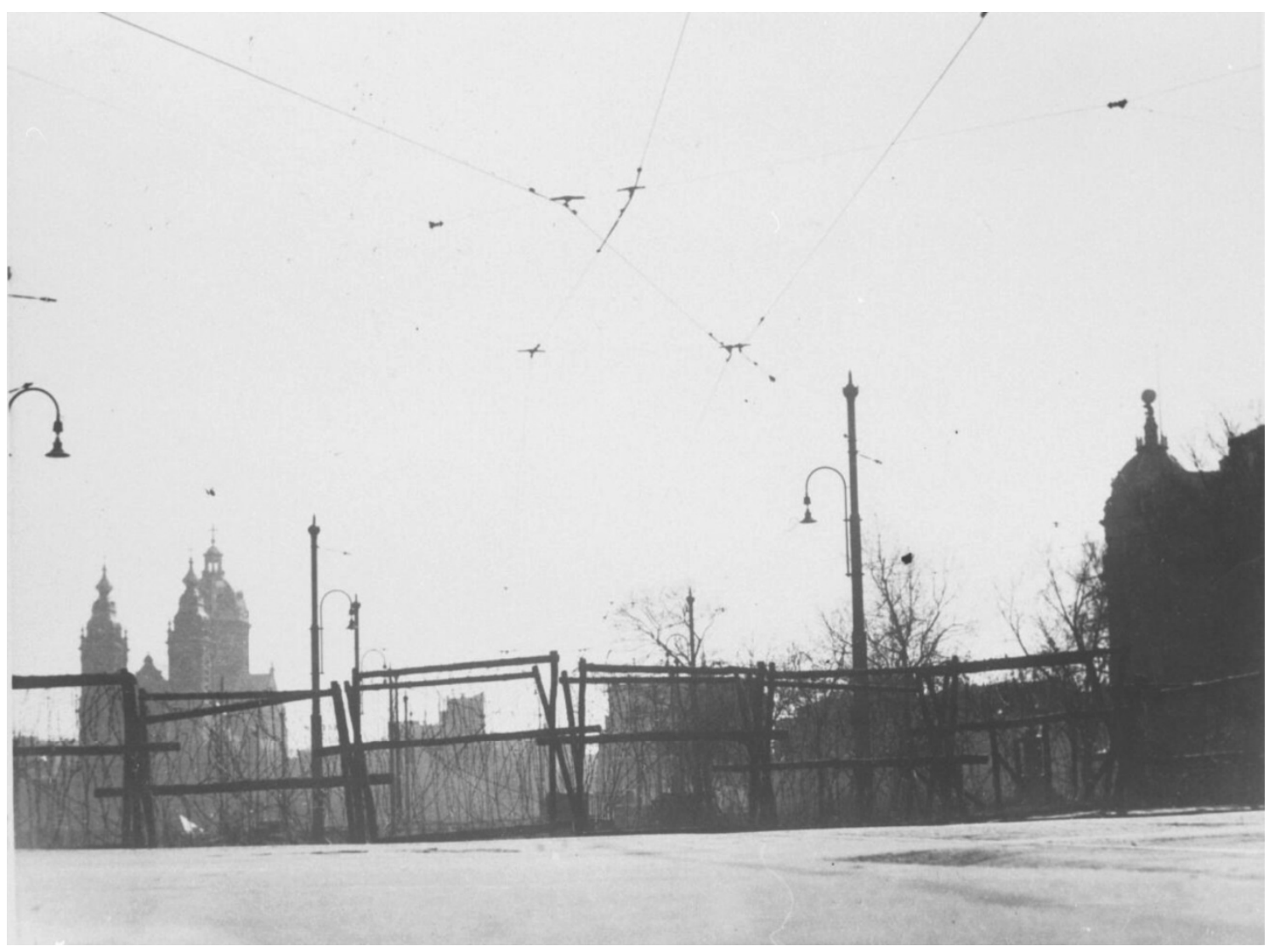

Fuente: NIOD Collection, 75728.

\section{LA CIUDAD Y EL ORDEN: RUPTURAS Y CONTINUIDADES EN LOS "REGÍMENES DE OCUPACIÓN".}

17 de julio de 1939, 17 horas. Rosario del Olmo, casada, natural de Madrid, periodista, de 27 años, fue conducida ante el inspector de guardia para que le fuera 
tomada declaración. Exactamente tres años antes había comenzado la sublevación contra la II República en el Protectorado de Marruecos. "El 17 a las 17" fue una de las consignas preferidas en los instantes previos al golpe de Estado, y la guerra que desencadenó había terminado con la ocupación de Madrid. Más de tres meses después de aquello, y rodeada por agentes del Cuerpo de Investigación y Vigilancia, Rosario se vio obligada a rememorar los momentos que definían su conducta en el pasado. Había sido detenida en su domicilio por "haber tenido noticias de hallarse oculta y de haber ejercido cargos de responsabilidad política en el Ministerio de Propaganda y Prensa". Y debido a las constantes repeticiones y aclaraciones que aparecen en su interrogatorio, éste debió estar repleto de interrupciones. "Que tiene grandes simpatías con (sic.) el Partido Comunista aunque no pertenece a él". "Que durante toda la guerra estuvo trabajando en el Ministerio de Estado, en la Subsecretaría de Propaganda y Prensa roja”. "Que no ha tenido actuación política de ninguna clase". "Que su marido se halla actualmente en Francia”. A pesar de que la transcripción sólo incluye las respuestas, es fácil imaginar las preguntas que le hicieron a Rosario y de qué estuvieron acompañadas $^{61}$.

Enviada a la cárcel de Ventas, los agentes ampliaron rápidamente las diligencias sobre la conducta de la detenida siguiendo las órdenes del juez militar de guardia del distrito de Chamberí, donde vivía Rosario, en una estrategia por reducir el ámbito de actuación de la justicia de ocupación y multiplicar su efectividad. Según el testimonio de Fernando Sanz, destinado a la Delegación de Propaganda y Prensa como infiltrado de la "Quinta Columna", era "persona de gran influencia", pues decidía qué telegramas eran enviados a la prensa extranjera, lo que le hacía creer que pertenecía "al Partido Comunista por haberla propuesto para el cargo que ostentaba un miembro de dicho partido político". Este estereotipo, configurado en una fecha tan temprana como el 18 de julio de 1939, marcó el resto del proceso. El informante parecía ser, al mismo tiempo, una persona cercana a Rosario, pues había presenciado la detención: "negaron en el domicilio de la detenida que se hallara allí", y sin embargo los agentes "penetraron en una habitación hallándose en ella a una joven que dijo ser hermana de ROSARIO DEL OLMO y que luego resultó ser la propia ROSARIO”. Además, como indicaba el final de

\footnotetext{
${ }^{61}$ AGHD, Sumario 52355, Caja 2983/5. Sigo esta referencia para cualquier información sobre su caso, si no se indica lo contrario.
} 
las diligencias, su aspecto era diferente. "En el porte físico de la detenida se ha operado una transformación notable (peinado, maquillaje, teñido de pelo) que se ha hecho voluntariamente para poder burlar la acción de la Justicia". Todo parecía indicar la culpabilidad de Rosario. Al menos según la justicia de ocupación franquista que, como ya se ha recordado, eliminó la distancia entre los hechos atribuidos y los probados, y equiparaba los rumores a la categoría de prueba incriminatoria ${ }^{62}$.

Aunque ella no lo sabía, Rosario había sido denunciada ya por dos de sus vecinos cuando la Auditoría repartió los formularios tras la entrada en la ciudad, acusada de haber incautado un piso para la Alianza de Intelectuales Antifascistas junto a la escritora María Teresa León ${ }^{63}$. La denuncia se incorporó al sumario más tarde, prueba de que la construcción del régimen de ocupación en Madrid también incluyó importantes continuidades a nivel punitivo. Las experiencias de Ámsterdam y París son particularmente interesantes porque ofrecen dos "momentos" completamente distintos. Después de mayo de 1940, y a pesar del aumento de la tensión dentro de la ciudad a medida que las medidas de Seyss-Inquart envalentonaban a las milicias del NSB, la colaboración de las autoridades civiles con la estructura de ocupación permitió una importante sensación de normalidad en la capital holandesa. En perspectiva, incluso la huelga de febrero de 1941 planteaba claras continuidades con el "alzamiento del Jordaan" de 1934 contra los recortes en el sistema de seguridad social de los Países Bajos. La reorganización de la policía se produjo únicamente después de la huelga, como consecuencia del desafío que supuso a efectos de control urbano y por iniciativa alemana ${ }^{64}$.

En mayo de 1945, sin embargo, el impacto de la ocupación aliada sobre la gestión del orden público no se hizo esperar. El debate sobre la conveniencia de restaurar el orden descentralizado de preguerra o mantener la centralización de herencia nazi protagonizó los momentos iniciales del ínterin militar, pero fue resuelto con relativa rapidez en el decreto del 8 de noviembre de 1945, por el que los alcaldes

\footnotetext{
62 Pablo Gil Vico, "Derecho y ficción: la represión judicial militar", en Violencia roja y azul. España, 1936-1950, ed. Francisco Espinosa Maestre (Barcelona, Crítica, 2010), 251-368.

${ }^{63}$ Archivo Histórico Nacional (AHN), FC-Causa General, 1357, Exp. 2, pp. 8-10.

${ }^{64}$ Cyrille Fijnaut et al., "The Impact of the Occupation on the Dutch Police", en The Impact of World War II on Policing in North-West Europe, ed. Cyrille Fijnaut (Leuven, Leuven University Press, 2004), 91132; Meershoek, "The Amsterdam Police...
} 
recuperaron autoridad sobre las fuerzas municipales y nacionales de policía, aun cuando éstas podían intervenir sobre la ciudad para restaurar el orden. La balanza se inclinó por una relativa centralización del sistema, mayor aún si se compara con el de preguerra, sobre todo porque el decreto no confería ninguna función a los fiscales del distrito. La influencia de la ocupación también se proyectó en la importancia que empezó a otorgarse a la gestión de la información. En paralelo a la aprobación del decreto se creó el Servicio Central de Seguridad, una agencia de inteligencia independiente del Ejército y destinada a la gestión de información de carácter político, que debía ser obtenida mediante colaboración con la policía municipal ${ }^{65}$.

Pero, por encima de todo, la "liberación" de Ámsterdam al final de la IIGM significó una ruptura mayor que su "ocupación" al inicio cuando los vecinos vieron cómo los militares entraban en sus casas, se hacían cargo del abastecimiento de la ciudad y la resolución de sus problemas dependía de su relación con ellos. Aunque breve, la labor del Ejército en 1945 en la pacificación del orden fue clave para que la administración holandesa de posguerra se empleara en la depuración de la policía. Entre los 2.053 agentes con los que contaba el cuerpo de policía en Ámsterdam, 628 fueron investigados (30,6\%), de los cuales $351(17,1 \%)$ fueron expulsados y $113(5,5 \%)$ expedientados. Es importante recordar, además, que la policía municipal apenas tuvo implicación directa el marco represivo de ocupación. Los hombres elegidos por Rauter y Tulp, relacionados en mayor o menor medida con el NSB o incluso miembros de las SS, fueron directamente expulsados ${ }^{66}$.

La depuración de posguerra en las agencias encargadas de gestionar el orden en la ciudad fue uno de los elementos que marcaron rupturas y continuidades con los sucesivos regímenes de ocupación. También la relación con la población civil. En junio de 1940, a la rendición del Ejército francés le siguió un gran éxodo en París. Pero el miedo en las casas y el silencio en las calles ante la posibilidad de que se repitiera el escenario de 1870 no duró muchos días. Entre los objetivos de la administración alemana también estaba recuperar lo antes posible el rostro normal de la ciudad, y no hacer recaer la ocupación únicamente sobre la fuerza y la represión. Una actitud que se

\footnotetext{
${ }^{65}$ Romijn, “Administration Under Occupation...; Fijnaut et al., “The Impact of...

${ }^{66}$ La plantilla tomada como base corresponde a la del 1 de febrero de 1944, según Croes, "The Dutch Police..., 77-79. Para lo anterior, véase Peter Romijn, “«Liberators and Patriots». Military Interim Rule and the Politics of Transition in Netherlands, 1944-1945”, en Seeking Peace..., 117-144.
} 
extendió más allá de los primeros días de ocupación, puesto que según Simone de Beauvoir el verano de 1940 trajo consigo las mismas imágenes a lo largo del Sena, aun con insólitos personajes: “Gente nadando y navegando en la Grande Jatte. Ambiente de vacaciones, aunque algo agresivo. Cuando el coche se detuvo cerca de un puente, un soldado alemán nos tiró una tableta de chocolate desde un camión. [...] Aún no he visto síntomas de odio real en nadie". Incluso algunos delitos perseguidos en Alemania, como la homosexualidad, no eran tenidos en cuenta en París ${ }^{67}$.

En el testimonio de Simone de Beauvoir se intuye una cierta fluidez en la relación con los ocupantes, una experiencia que estuvo atravesada por diferentes realidades, como la fascinación que algunos podían sentir hacia la ciudad en términos culturales y simbólicos. El diario de Ernst Jünger, el famoso escritor veterano de la I Guerra Mundial, destinado en Alto Mando Militar desde 1941, es una importante prueba de ello. Asistente asiduo de las mejores librerías de la ciudad y de la ComédieFrançaise, invitado por ilustres de la intelectualidad parisina, llegó a visitar a Picasso en su taller. También era un reconocido salonnier, entorno donde coincidió con los escritores Drieu La Rochelle y Cocteau o el editor Gaston Gallimard ${ }^{68}$. Su sociabilidad estuvo mediada por la clase social a la que pertenecían él y sus acompañantes, pero en la estructura del régimen de ocupación la necesidad de que la ocupación no fuera conflictiva entre la población civil era fundamental puesto que, según Peter Lieb y Robert Paxton, los alemanes nunca estuvieron en condiciones de mantener el orden por sí mismos. Un objetivo que fue alejándose progresivamente cuando, a partir de 1942, la "zona libre" de Vichy se incluyó entre los territorios de gestión directa y las acciones de la Resistencia se hicieron más comunes ${ }^{69}$.

El colapso del régimen de ocupación nazi sobrevino cuando quedó patente que ya no podía asegurar la reproducción del orden urbano, y las condiciones de vida de la población se volvieron desesperadas. En los días previos a la "segunda ocupación", en agosto de 1944, el Comité Parisino de la Liberación incluyó entre sus objetivos los depósitos de gasolina y víveres de la guarnición alemana. Lo primero suponía un claro

\footnotetext{
${ }^{67}$ Cointet, Paris 40-44..., 59; Rosbottom, When Paris..., 145-150. El testimonio de Simone de Beauvoir, en David Pryce-Jones, Paris in the Third Reich (London, Collins, 1981), 23

${ }^{68}$ Ernst Jünger, Journaux de guerre. Tome II, 1939-1948 (Paris, Gallimard, 2008), 23, 41, 42, 123, 125 , $148,191$.

${ }^{69}$ Lieb y Paxton, "Maintenir l'ordre...; Cointet, Paris 40-44..., 66-72.
} 
objetivo ofensivo (la confección de cócteles molotov, cuyas instrucciones acompañaban la propia orden de requisa), pero ambas órdenes atacaban a la propia gestión de la ciudad, uno de los principales temores de Dietrich von Choltitz, gobernador militar del Gran París. En sus propias palabras, "para que el abastecimiento de la capital pueda asegurarse, se deben mantener el orden y la calma". Para ello reclamó la continuidad de los servicios públicos, incluida la policía, así como los bancos, las tiendas y la actividad industrial $^{70}$. La estrategia de la Resistencia intentaba profundizar en los efectos de la huelga convocada contra la administración alemana, que había comenzado el 10 de agosto y había desbaratado importantes resortes del gobierno de la ciudad, pues a los ferroviarios se les unió la propia policía ${ }^{71}$.

Las circunstancias que rodearon a la "Liberación" marcaron una importante ruptura con la situación previa en términos de orden público, también desde una perspectiva institucional. La desesperada situación de los miembros de la Resistencia en el interior de la ciudad, escasamente armados, se despejó el día 25, cuando las tropas comandadas por el general Léclerc entraron en la ciudad. Pero, a pesar de lo que comúnmente se cree, estuvieron auxiliadas por la $4^{\mathrm{a}}$ División estadounidense, que procedió a la ocupación de la zona oriental de la ciudad mientras los franceses hacían lo propio en los distritos occidentales, los de mayor presencia alemana en los años previos. Controlados los accesos a la ciudad, los cruces de avenidas y las principales estaciones de tren y metro, todo parecía en orden. Pero la ocupación no había sido, contrariamente al deseo de De Gaulle, un asunto exclusivamente doméstico. El general Koenig, nombrado gobernador militar de la ciudad y comandante de la Región de París, recordó en su proclamación del 27 de agosto los “imperiosos deberes" en materia de orden público. No fue escuchado, y el Comité de Liberación se vio obligado a denunciar como actos "cómplices del enemigo" el pillaje en las tiendas y los depósitos capturados, que debían ser "reservados al conjunto de la población y repartidos bajo el control de las autoridades de la República". En un contexto dominado por el temor a un bombardeo aéreo y a que la "histeria de la liberación" se contagiara a las tropas de ocupación, las ambiciones políticas y militares de De Gaulle y Léclerc, respectivamente, sobre la

\footnotetext{
${ }^{70}$ Musée de la Libération de Paris (MLP), 2008.61. Para las órdenes de requisa, MLP, 1990.56 y 2010.4.33.

${ }^{71}$ Simon Kitson, "The Police in the Liberation of Paris", en The Liberation of France. Image and Event, ed. H. R. Kedward y Nancy Wood (Oxford : Herndon, Berg, 1995), 43-56.
} 
importancia del control de la capital de Francia generaron una gran tensión en el Alto Mando aliado. El gobierno fue transferido finalmente a los franceses, que siguieron enfrentándose a problemas clave como el abastecimiento de comida, carbón, gasolina o medicinas y a la gestión del transporte ${ }^{72}$.

En el caso de Madrid, tanto las rupturas como las continuidades fueron consustanciales al régimen de ocupación y se proyectaron sobre el orden posconflicto. La instrucción del sumario contra Rosario del Olmo señalaba la reconversión del espacio público de preguerra bajo criterios de orden público, especialmente para las mujeres. La moralidad del nuevo Estado franquista se posó sobre ellas, protagonistas del "desorden" al que se asociaban las décadas previas ${ }^{73}$. El caso fue transferido el caso en diciembre de 1939 al Tribunal Especial de Prensa y Propaganda, y los nuevos interrogatorios e informes solicitados ahondaron en el perfil público de Rosario, que reconoció haber escrito en medios como La Libertad o El Imparcial, actividad "que algunas veces se refería a política" ${ }^{74}$. Meses más tarde, el comisario jefe del distrito de Hospicio comunicó que también había sido redactora del periódico Claridad, donde "tuvo un cargo importante durante el dominio rojo". Por todo ello, Rosario era "persona considerada como elemento peligroso para el Régimen nacional", ya que desde su puesto de trabajo había "insultado y amenazado a las personas de derechas, y ha hecho gran propaganda roja". A pesar de que el informe reconocía que no había "tomado parte en hecho delictivo", el objetivo de la instrucción era situar la conducta de Rosario en alguno de los artículos del bando de guerra. "Se sabe que durante la guerra ha llevado a su domicilio efectos y ropas que no ha podido justificar". Como en tantos otros casos, el rumor sustituyó a las pruebas y construyó los márgenes de las conductas aceptables.

En realidad, Rosario no sólo pagó su protagonismo en la defensa de Madrid, también una realidad mayor: la incorporación de las mujeres a puestos de responsabilidad y a lugares de gran visibilidad pública. Las normas morales del "nuevo"

\footnotetext{
72 MLP, 1994.179 y AFF3115; Martin Blumenson, United States Army in World War II. European Theater of Operations. Breakout and Pursuit (Washington DC, Center of Military History, 1961), 614628.

${ }^{73}$ Ramiro Trullén Floria, España trastornada. La identidad y el discurso contrarrevolucionario durante la II República y la Guerra Civil (Madrid, Akal, 2016), 63-88, 113-138 y 191-216.

${ }^{74}$ Rosario fue la autora de la entrevista a Antonio Machado en que aparece su famosa fotografía en el Café de las Salesas, realizada por Alfonso Sánchez García, "Alfonso". La entrevista se tituló "Los deberes del arte en el momento actual", publicada en La Libertad, 12 de enero de 1934. Agradezco a Ana Fernández-Cebrián esta información.
} 
tiempo se proyectaban incluso sobre el propio cuerpo femenino, como ya recordara Aurora Morcillo, puesto que la pureza femenina era uno de los fundamentos del orden, en tanto que principio de reproducción de la propia sociedad. Pero que la masculinidad tal y como era sancionada por el régimen franquista fuera uno de los argumentos de la "reconquista" de la ciudad, identificada como espacio privilegiado del desorden, no implica que las mujeres fueran meros sujetos pasivos ${ }^{75}$. Tampoco a efectos de orden público. Tras la ocupación, el $42 \%$ de las denuncias que contenían los formularios de interrogatorio entregados en las porterías del distrito de Chamberí fueron emitidas por mujeres, y en los meses siguientes fue normal que los informes de conducta sobre las personas detenidas también incluyeran testimonios de vecinas, prueba de la clara orientación de la dictadura como régimen de control $^{76}$.

De hecho, mientras la instrucción del caso contra Rosario del Olmo dejaba claro que entre sus culpas figuraba la de ser una mujer con presencia pública, tanto la estructura de la Policía franquista como su propio modus operandi se adaptaban al mundo urbano. Y lo hacían al calor del desafío que suponía la ciudad en cuanto a la gestión punitiva de la información para contrarrestar el anonimato. Primero, debido a la importancia de la colaboración entre el Servicio de Información y Policía Militar (SIPM), el espionaje militar franquista, y el Servicio de Información de la Auditoría de Guerra, donde estaban empleados sus agentes, en la creación de la nueva Dirección General de Seguridad. Y segundo, por la extensión de los informes de conducta políticosocial como método policial, que incluía la averiguación de detalles cotidianos a partir del concurso de vecinos y conocidos. La filiación política, la actuación durante la guerra y los posibles cargos que la persona sospechosa hubiese podido ejercer eran siempre las primeras averiguaciones en estos dispositivos, que hacían depender la conceptuación pública y privada de la propiamente policial y religiosa ${ }^{77}$.

\footnotetext{
${ }^{75}$ Aurora Morcillo, En cuerpo y alma. Ser mujer en tiempos de Franco (Madrid, Siglo XXI, 2015); Mary Vincent, "La reafirmación de la masculinidad en la Cruzada franquista", Cuadernos de Historia Contemporánea, 28 (2006), 135-151. La reconstrucción del espacio público en términos de masculinidad también protagonizó la Francia "liberada". Puede verse el ya clásico Fabrice Virgili, La France "virile". Des femmes tondues à la Libération (Paris, Éditions Payot \& Rivages, 2000).

${ }^{76}$ AHN, FC-Causa General, 1357, Exp. 1-4 y Alejandro Pérez-Olivares, "El franquismo, ¿un régimen de control? Experiencias, dispositivos y espacios (desde el Madrid ocupado)", Historia Social, 97 (2020), 61-78.

${ }^{77}$ Alejandro Pérez-Olivares, Victoria y control en el Madrid ocupado. Los del Europa (1939-1946), (Madrid, Traficantes de Sueños, 2018).
} 
La innegable continuidad de la guerra en el nuevo tiempo se hizo patente en el peso del pasado a efectos punitivos. Josefa tenía 44 años cuando, el 30 de junio de 1939, decidió avalar la conducta de Ángel González Siguero, un carbonero que se encontraba en prisión preventiva, procesado en una causa colectiva ${ }^{78}$. Le constaba que era "persona afecta al Glorioso Movimiento Nacional”, un testimonio favorable que repitió un año más tarde, el 16 de julio de 1940. La última ocasión en que fue reclamada por la justicia franquista habían pasado cinco años desde que esta portera aceptara por primera vez el riesgo de responder por la conducta de Ángel, que iba a ser juzgado por segunda vez. Tal era el celo de aquel régimen sobre los comportamientos de los habitantes de la ciudad. Aquella última vez Josefa se definió a sí misma como "jefe político" de la casa que habitaba. Miembro del partido único, formaba parte de la estrategia de control diseñada por el Ejército de Ocupación en 1939 para dominar la vida en los barrios ${ }^{79}$. Pero tras ese último aval, el tercero, hubo otro documento más. El de Antonio Pérez Portella, Inspector de Barrios de FET y de las JONS del distrito que compartía con Josefa, el que aprobaba el informe de aquella portera. "Y para que conste y acreditar su condición de Jefe Político de la Organización de Barrios de este Distrito, expido el presente certificado". Era el 13 de marzo de 1944. Cinco años después de su ocupación, en Madrid quedaba claro que la sospecha sobre cualquier conducta, herencia continuada desde la guerra, era una de las formas en que se manifestaba el orden impuesto en la ciudad.

\section{REFLEXIONES FINALES.}

En las páginas anteriores he mostrado la importancia de reinterpretar desde el prisma de la historia urbana la diversidad de uno de los fenómenos que han protagonizado la historiografía europea en las últimas décadas: las ocupaciones en el marco de la "guerra total". He seleccionado tres ciudades, Madrid, Ámsterdam y París, para reivindicar la urbanidad (y, dentro de ella, la espacialidad) de los regímenes de ocupación al considerar realidades como el anonimato, la movilidad, la sociabilidad o la propia escala urbana en el análisis de los regímenes de ocupación, lo que permite

\footnotetext{
${ }^{78}$ AGHD, Sumario 13769, Legajo 4110. Sigo esta referencia si no se indica lo contrario.

${ }^{79}$ AGMAV, Caja 2552, Carpeta 48, fol. 5 y Alejandro Pérez-Olivares, Madrid cautivo..., 79-90.
} 
trascender el tradicional interés por las disposiciones oficiales o las autoridades. En este sentido, he identificado tres argumentos para replantear algunos de los principales fenómenos que han definido los acercamientos a este contexto: el tipo de administración de ocupación para la "paradoja holandesa" respecto al Holocausto, la extensión de los faux policiers en la capital francesa para la colaboración y la relevancia de las conductas pasadas para entender la naturaleza represiva de la dictadura y su adecuación al mundo urbano. Poner en perspectiva estas tres ciudades no sólo permite resaltar sus similitudes y diferencias sino, principalmente, las particularidades de los retos asociados a los propios regímenes de ocupación: el procesamiento de información como requisito para combatir el anonimato, el control de la movilidad y la gestión de los recursos para el mantenimiento del orden, la integración de las autoridades locales en la gestión de la ocupación o la colaboración de la población en el difícil equilibrio del orden público. Desde este punto de vista, puede decirse que las ciudades hicieron de estos regímenes una realidad cambiante, disputada por realidades y sujetos peculiares.

La administración civil hizo de la ocupación holandesa de 1940 un contexto propicio a la imposición ideológica que, sin embargo, se encontró con varias dificultades para identificar a la población judía de Ámsterdam. La colaboración de la población fue tan necesaria como en Madrid un año antes, pero adquirió formas distintas. En el primer caso dio paso a la creación de una institución nueva, el Consejo Judío; en el segundo, la justicia del nuevo Estado franquista estuvo vehiculada por el propio Ejército de ocupación. En el París alemán la colaboración entre diversas agencias de control incluyó a miembros de la población civil que se hacían pasar por policías, un fenómeno que responde tanto al endurecimiento de las condiciones de vida como al cambio de orientación en el curso de la guerra. En los tres casos, las autoridades de ocupación pretendieron combatir el anonimato y la movilidad propios de la ciudad introduciendo salvoconductos obligatorios para circular y otros dispositivos de identificación.

Las rupturas y las continuidades asociadas a la ocupación influyeron en la estabilidad de una administración cuya principal preocupación fue siempre mantener el orden. Cuando eso no fue posible en Ámsterdam, las condiciones del régimen de ocupación nazi se endurecieron y la policía holandesa fue obligada a colaborar en la deportación de los judíos de la ciudad. En el París de 1944, la “Liberación” también 
debe comprenderse como un problema de orden público: primero como una de las causas que permiten explicar su ocupación por los aliados, después como una de las realidades que explican su difícil gestión en las semanas siguientes. Pero quizá sea en el Madrid franquista donde ese cúmulo de rupturas y continuidades se expresaron de forma más dramática, pues formaron parte inseparable de la reorientación del espacio público hacia criterios de orden público. Así lo demuestra el desempeño de la justicia de ocupación y la propia creación de la Policía, que hizo del examen de las conductas pasadas su motor de actuación.

Puede que muchas personas recordaran los años previos a la ocupación de su ciudad y los asociaran a "los buenos viejos tiempos", pero para otras supuso una oportunidad para prosperar. Entre los años 30 y 40, la supervivencia convivió de muchas formas con la retribución; la persecución, con la colaboración; la intención de gobernar, con la posibilidad del desorden. Madrid, Ámsterdam y París vieron cómo el final de la guerra trajo la ocupación, y que eso no fue sinónimo de calma o tranquilidad. De una vida ordenada, en suma, desde la perspectiva de los ocupantes y según su deseo. Puede que ese recuerdo, a medio camino entre la nostalgia y el trauma, no fuera sino la expresión de una ciudad fantasma. O puede que lo fuera, en cambio, el de una vida enfrentada a todas las normas, viejas y nuevas, que definieron un tiempo de excepción. Quizá sea esa sensación, y no otra, la que conecta aquel tiempo y el nuestro y crea, a la vez, el distanciamiento necesario para toda perspectiva histórica. Marguerite Duras identificó en su diario la paz de la ocupación con el dolor, y allí la describió "como una noche profunda, también el comienzo del olvido" ${ }^{\circ 0}$. Las respuestas que podamos encontrar sobre las ocupaciones urbanas de hace décadas dependerán, también, de las preguntas que podamos hacernos sobre nuestras propias ciudades-fantasma hoy.

A Peter Romijn, por su generosidad sin límites en el "centro mágico”.

\section{BIBLIOGRAFÍA.}

Agamben, Giorgio, Estado de excepción. Homo sacer II, 1, Madrid, Pre-Textos, 2010.

\footnotetext{
${ }^{80}$ Marguerite Duras, La douleur (Paris, POL, 1985), 58.
} 
Auda, Gregory, Les Belles Années du 'milieu' 1940-1944. Le grand banditisme dans la machine répressive allemande en France, Paris, Michalon, 2013.

Bardèche, Maurice, Souvenirs, Paris, Buchet-Chastel, 1993.

Beevor, Anthony y Cooper, Artemis, París. Después de la Liberación, 1944-1949, Barcelona, Crítica, 2004.

Blom, J. C. H., "The Persecution of the Jews in the Netherlands: A Comparative Western European Perspective", European History Quarterly, 19, 3 (1989), 333351.

Blumenson, Martin, "Politics and the Military in the Liberation of Paris", Parameters, 28, 2 (1998), 4-14.

--, United States Army in World War II. European Theater of Operations. Breakout and Pursuit, Washington DC, Center of Military History, 1961.

Boldorf, Marcel y Okazaki, Tetsuki (eds.), Economies Under Occupation. The Hegemony of Nazi Germany and Imperial Japan in World War II, London: New York, Routledge, 2015.

Box, Zira, España, año cero. La construcción simbólica del franquismo, Madrid, Alianza Editorial, 2010.

Brioche, François, Dictionnaire de la Collaboration. Collaborations, compromissions, contradictions, Paris, Belin, 2014.

Burrin, Philippe, La France à l'heure allemande, 1940-1944, Paris, Seuil, 1995.

Carlton, Eric, Occupation. The Policies and Practices of Military Conquerors, Savage, Barnes \& Noble Books, 1992.

Castillo, Fernando, Noche y niebla en el París ocupado: traficantes, espías y mercado negro, Madrid, Fórcola, 2012.

Charbonneau, Henry, Les Mémoires de Porthos, t. II, Paris, Desroches, 1969.

Cocteau, Jean, La machine à écrire. Théâtre, Vol. II, Paris, Gallimard, 1983.

--, Journal 1942-1945, Paris, Gallimard, 1989.

Cointet, Jean-Paul, Paris 40-44, Paris, Perrin, 2001. 
Croes, Marnix, "The Dutch Police Force and the Persecution of the Jews in the Netherlands", en De Wever, Bruno; Van Goethem, Herman y Wounters, Nico (eds.), Local Government in Occupied Europe (1939-1945), Gent, Academia Press, 2006, 67-81.

Davies, Peter, France and the Second World War. Occupation, collaboration and resistance, London : New York, 2001.

De Haan, Ido, "Imperialism, Colonialism and Genocide. The Dutch Case for an International History of the Holocaust", BMGN - Low Countries Historical Review, 125, 2-3 (2010), 301-327.

De Jong, Louis, The Netherlands and Nazi Germany, Cambridge : London, Harvard University Press, 1990.

De Schaepdrijver, Sophie, "Military occupations, 1914-1945", en Chickering, Roger; Showalter, Dennis y Van De Ven, Hans (eds.), The Cambridge History of War, Vol. IV. War and the Modern World, Cambridge, Cambridge University Press, 2012, 236-256.

Debrash, Odile, L'occupation militaire, Paris, Librairie générale de droit et de jurisprudence, 1962.

Desprairies, Cécile, Paris dans la collaboration, Paris, Seuil, 2009.

Drake, David, Paris at War. 1939-1944, Cambridge, Harvard University Press, 2015.

Duras, Marguerite, La douleur, Paris, POL, 1985.

Espinosa Romero, Jesús, "La Delegación del Estado para la Recuperación de Documentos en Madrid", en Oviedo Silva, Daniel y Pérez-Olivares García, Alejandro (coords.), Madrid, una ciudad en guerra (1936-1948), Madrid, Los Libros de la Catarata, 2016, 133-158.

Fijnaut, Cyrille et al., "The Impact of the Occupation on the Dutch Police”, en Fijnaut, Cyrille (ed.), The Impact of World War II on Policing in North-West Europe, Leuven, Leuven University Press, 2004, 91-132.

Gil Vico, Pablo, "Derecho y ficción: la represión judicial militar", en Espinosa Maestre, Francisco, Violencia roja y azul. España, 1936-1950, Barcelona, Crítica, 2010, 251-368. 
Gildea, Robert, Marianne in Chains. Daily Life in the Heart of France During the German Ocupation. London, MacMilan, 2002.

Gregory, Ian N. y Geddes, Alistair, "Conclusions: From Historical GIS to Spatial Humanities: Challenges and Opportunities", en Toward Spatial Humanities. Historical GIS \& Spatial History, Ed. Gregory, Ian N. y Geddes, Alistair, Bloomington: Indiana University Press, 2014, 172-185.

Hills, Alice, Policing Post-Conflict Cities, London : New York, Zed Books, 2009.

Hoffmann, Stephan-Ludwig et al, "Introduction. Seeking Peace in the Wake of War: Europe, 1943-1947”, en Hoffmann, Stephan-Ludwig et al. (eds.): Seeking Peace in the Wake of War. Europe, 1943-1947, Amsterdam, Amsterdam University Press, 2015, 9-27.

Jansen, Ronald W., Anne Frank, Silent Witnesses. Reminders of a Jewish girl's life, Ámsterdam, RWJ, 2014.

Jünger, Ernst, Journaux de guerre. Tome II, 1939-1948, Paris, Gallimard, 2008.

Kitson, Simon, "The Police in the Liberation of Paris", en Kedward, H. R. y Wood, Nancy (ed.), The Liberation of France. Image and Event, Oxford : Washington DC, 1995, 43-56.

Lammers, Cor, "Levels of Collaboration: A Comparative Study of German Occcupation Regimes during the Second World War", The Netherlands Journal of Social Sciences, 31 (1995), 3-31.

Laub, Thomas J., After the Fall. German Policy in Occupied France (1940-1944), New York, Oxford University Press, 2010.

Lefebvre, Henri, La producción del espacio, Madrid, Capitán Swing, 2013 [1974].

Lieb, Peter y Paxton, Robert, "Maintenir l'ordre en France occupée. Combien de divisions?", Vingtième Siècle. Revue d'histoire, 4, 112 (2012), 115-126.

Lindeman, Yehudi y De Vries, Hans, "«Therefore Be Courageous Too». Jewish Resistance and Rescue in the Netherlands", en Henry, Patrick (ed.), Jewish Resistance Against the Nazis, Washington DC, The Catholic University of American Press, 2014. 
Meershoek, Guus, "The Amsterdam Police and the Persecution of the Jews", en Berenbaum, Michael y Peck, Abraham (Ed.), The Holocaust and History. The Known, the Unknon, the Disputed and the Reexamined, Bloomington : Indianapolis, Indiana University Press, 1998, 284-300.

Michman, Dan, "The Uniqueness of the Joodse Raad in the Western European Context", en Michman, Jozeph (ed.), Dutch Jewish History, Vol. III, Jerusalem, 1993, 371-380.

Moore, Bob, "Nazi Masters and Acomodating Dutch Bureaucrats: Working Towards the Führer", en McElligott, Anthony y Kirk, Tim (Ed.), Working Towards the Führer. Essays in Honour of Sir Ian Kershaw, Manchester : New York, Manchester University Press, 2003, 186-204.

Morcillo, Aurora, En cuerpo y alma. Ser mujer en tiempos de Franco, Madrid, Siglo XXI, 2015.

Mouré, Kenneth, “La Capitale de la Faim: Black Market Restaurants in Paris, 19401944”, French Historical Studies, 38, 2 (2015), 311-341. doi: https://doi.org/10.1215/00161071-2842590.

--, "The Faux Policier in the Occupied Paris", Journal of Contemporary History, 45, 1 (2010), 95-112. doi: https://doi.org/10.1177\%2F0022009409348965.

Noizet, Hélène, "Spaces and spatialities in Paris between the ninth and nineteeth centuries: urban morphology generated by the management of otherness", Urban History, $\quad 47, \quad 3 \quad$ (2020), 401-420. doi: https://doi.org/10.1017/S0963926820000231.

Oviedo Silva, Daniel, "«Juro por Dios y declaro por mi honor»: verdad, impostura y estrategias autoexculpatorias en las declaraciones de la posguerra madrileña", en Oviedo Silva, Daniel y Pérez-Olivares García, Alejandro (coords.), Madrid, una ciudad en guerra (1936-1948), Madrid, Los Libros de la Catarata, 2016, 159214.

Oviedo Silva, Daniel y Pérez-Olivares, Alejandro, “¿Un tiempo de silencio? Porteros, inquilinos y fomento de la denuncia en el Madrid ocupado", Studia Historica. Historia Contemporánea, 34 (2016), 301-331. 
Pérez-Olivares, Alejandro, "Objetivo Madrid: planes de ocupación y concepción del orden público durante la Guerra Civil española", Culture \& History Digital Journal, 4, 2 (2015). doi: http://dx.doi.org/10.3989/chdj.2015.019.

--, Victoria y control en el Madrid ocupado. Los del Europa (1939-1946), Madrid, Traficantes de Sueños, 2018.

--, "El franquismo, ¿un régimen de control? Experiencias, dispositivos y espacios (desde el Madrid ocupado)", Historia Social, 97 (2020), 61-78.

--, Madrid cautivo. Ocupación y control de una ciudad (1936-1948), Valencia, Publicacions de la Universitat de València, 2020.

Presser, Jacob, Ashes in the Wind. The Destruction of the Dutch Jewry, Detroit, Wayne State University Press, 1988.

Pryce-Jones, David, Paris in the Third Reich, London, Collins, 1981.

Rodger, Richard Rau, Susanne, "Thinking spatially: new horizons for urban history", Urban History, 47, 3 (2020), 372-383. doi: https://doi.org/10.1017/S0963926820000218.

Romijn, Peter, "«Liberators and Patriots». Military Interim Rule and the Politics of Transition in Netherlands, 1944-1945", en Hoffmann, Stephan-Ludwig; Kott, Sandrine; Romijn, Peter y Wieviorka, Olivier (eds.), Seeking Peace in the Wake of War. Europe, 1943-1947, Amsterdam, Amsterdam University Press, 2015, 117-144.

--, "«The Lesser Evil». The case of the Dutch local authorities and the Holocaust", en VV. AA., The Persecution of the Jews in the Netherlands, 1940-1945, Ámsterdam, NIOD : Vossiuspers UvA, 2012.

--, "Ambitions and Dilemmas of Local Authorities in the German-Occupied Netherlands, 1940-1945", en De Wever, Bruno; Van Goethem, Herman y Wounters, Nico (eds.), Local Government in Occupied Europe (1939-1945), Gent, Academia Press, 2006.

--, "Did Soldiers Become Governors? Liberators, Resistance and the Reconstruction of Local Government in the Liberated Netherlands, 1944-1945", en Brower, 
Charles F. (ed.), World War II in Europe: The Final Year, New York, St. Martin's Press, 1998.

--, "Managing the integration of the occupied Dutch territories in Hitler's empire", en Eigner, Peter; Matis, Herbert y Resch, Andreas (Hg.), Entrepeneurship in schwrierigen Zeiten. Unternehmertuum, Karrieren und Umbrüche während der ersten Hälfte des 20. Jahrhunderts, Wien, Liet Verlag, 2013, 309-330.

--, "The Experience of the Jews in the Netherlands during the German Occupation", en Israel, Jonathan y Salverd, Reinier (eds.), Dutch Jewry. Its History and Secular Culture (1500-2000), Leiden, Brill, 2002, 253-271.

Rosbottom, Donald, When Paris Went Dark. The City of Light Under German Occupation, 1940-44, London, John Murray, 2014.

Schwartz, Paula, "The politics of food and gender in occupied Paris", Modern \& Contemporary France, 7, 1 (1999), 35-45. doi: https://doi.org/10.1080/09639489908456468.

Soja, Edward, Thirdspace. Journeys to Los Angeles and Other Real-and-Imagined Places, Malden, Blackwell, 1996.

Steenkamp, Christina, Violence and Postwar Reconstruction. Managing Insecurity in the Aftermath of Peace Accords, London : New York, Tauris, 2009.

Tartakowsky, Danielle, "Les polices en pays occupés ou sous tutelle”, en Berlière, JeanMarc y Peschanski, Denis (Dir.), Pouvoirs et polices au XXe siècle, Bruxelles: Éditions Complexe, 1997, 127-135.

Tönsmeyer, Tatjana; Haslinger, Peter y Laba, Agnes (Eds.), Coping with Hunger and Shortage under German Occupation in World War II, London, Palgrave Macmillan, 2018.

Trullén Floria, Ramiro, España trastornada. La identidad y el discurso contrarrevolucionario durante la II República y la Guerra Civil, Madrid, Akal, 2016.

Van Der Molen, Henk, "Amsterdam offers resistance". Disponible on-line en https://www.tracesofwar.com/articles/2929/February-strike-February-25th-and26th-1941.htm 
Vastenhout, Laurien, The Holocaust and the German Occupation of the Netherlands from the Perspective of Dutch Jewish Survivors. Tesis de Máster, Universiteit van Amsterdam, 2014.

Vincent, Mary; "La reafirmación de la masculinidad en la Cruzada franquista", Cuadernos de Historia Contemporánea, 28 (2006), 135-151.

Vinen, Richard, "False Policeman, Real Crooks, and Fictional Detectives in Paris during the Occupation", Historically Speaking, 8, 3 (2007), 31-32. doi: http://doi.org/10.1353/hsp.2007.0077

--, The Unfree French. Life Under Occupation, London, Penguin, 2007.

Virgili, Fabrice, La France "virile". Des femmes tondues à la Libération, Paris, Éditions Payot \& Rivages, 2000.

Wettstein, Adrian, "Urban Warfare Doctrine on the Eastern Front", en Kay, Alex J.; Rutherford, Jeff y Stahel, David, Nazi Policy on the Eastern Front, 1941. Total War, Genocide and Radicalization. Rochester: University of Rochester Press, 2012, 45-72.

Windig, Ad, Amsterdam, from Occupation to Liberation, Eindhoven, Kempen, 1993.

Winter, Jay y Robert, Jean-Louis, Capital Cities at War. Paris, London, Berlin: 19141919, Cambridge, Cambridge University Press, 1997. 